\title{
Multisystem inflammatory syndrome in children and Kawasaki disease: a critical comparison
}

Chetan Sharma $\mathbb{1}^{1,12 \otimes}$, Madhusudan Ganigara $\mathbb{1}^{2,12}$, Caroline Galeotti ${ }^{3}$, Joseph Burns ${ }^{4}$, Fernando M. Berganza ${ }^{5}$, Denise A. Hayes ${ }^{6}$, Davinder Singh-Grewal', Suman Bharath ${ }^{8}$, Sujata Sajjan ${ }^{9}$ and Jagadeesh Bayry (10) ${ }^{10,11 凶}$

Abstract $\mid$ Children and adolescents infected with severe acute respiratory syndrome coronavirus 2 (SARS-CoV-2) are predominantly asymptomatic or have mild symptoms compared with the more severe coronavirus disease 2019 (COVID-19) described in adults. However, SARS-CoV-2 is also associated with a widely reported but poorly understood paediatric systemic vasculitis. This multisystem inflammatory syndrome in children (MIS-C) has features that overlap with myocarditis, toxic-shock syndrome and Kawasaki disease. Current evidence indicates that MIS-C is the result of an exaggerated innate and adaptive immune response, characterized by a cytokine storm, and that it is triggered by prior SARS-CoV-2 exposure. Epidemiological, clinical and immunological differences classify MIS-C as being distinct from Kawasaki disease. Differences include the age range, and the geographical and ethnic distribution of patients. MIS-C is associated with prominent gastrointestinal and cardiovascular system involvement, admission to intensive care unit, neutrophilia, lymphopenia, high levels of IFN $\gamma$ and low counts of naive $\mathrm{CD} 4^{+} \mathrm{T}$ cells, with a high proportion of activated memory $\mathrm{T}$ cells. Further investigation of MIS-C will continue to enhance our understanding of similar conditions associated with a cytokine storm.

Our understanding of the coronavirus disease 2019 (COVID-19) pandemic caused by the novel severe acute respiratory syndrome coronavirus 2 (SARS-CoV-2) has improved greatly since the first human cases were reported in December 2019 in Wuhan City, China ${ }^{1,2}$. COVID-19 is known to involve multiple organ systems, with the major disease burden resulting from respiratory, cardiovascular, thrombotic and neurological complications $^{3-5}$. Cellular entry of SARS-CoV-2 depends on binding of the viral spike (S) protein to cellular receptors such as angiotensin-converting enzyme 2 (ACE2) receptor, which is expressed in multiple organ systems $\mathrm{s}^{6,7}$, and on S-protein priming by host-cell proteases ${ }^{8,9}$. In some individuals these steps are followed by a cascade of inflammatory events, resulting in a 'cytokine storm" This massive pro-inflammatory cellular and cytokine response is a feature of patients with severe COVID-19 disease $^{10}$.

Although morbidity and mortality from primary COVID-19 infection have remained limited in children, we have witnessed the emergence of a new inflammatory disorder associated with COVID-19, termed multisystem inflammatory syndrome in children (MIS-C) in the USA and paediatric inflammatory multisystemic syndrome (PIMS) in Europe ${ }^{11-15}$. Current evidence suggests that MIS-C is a post-infectious, immunologically mediated disorder related to prior SARS-CoV-2 exposure or infection ${ }^{16-18}$. Epidemiological, clinical and immunological investigations have revealed that MIS-C has phenotypic similarities to Kawasaki disease, a childhood inflammatory vasculitis, and it has been suggested that SARS-CoV-2 acts as an additional infectious trigger of Kawasaki disease, leading to an exaggerated phenotype along the same disease spectrum. However, in this Review we present evidence that although MIS-C has some features that overlap with Kawasaki disease, they are distinct syndromes that differ in degrees of hyperinflammation and dysregulated immune responses (TABLE 1).

\section{Overview of Kawasaki disease}

Kawasaki disease is a paediatric, self-limited, systemic inflammatory vasculitis that was first described in 1967 in Japan by Dr Tomisaku Kawasaki ${ }^{19}$. The most important long-term sequelae of Kawasaki disease relate to abnormalities of the coronary artery, and it is now the 


\section{Key points \\ - Multisystem inflammatory syndrome in children (MIS-C) is characterized by exaggerated innate and adaptive immune responses following infection with severe acute respiratory syndrome coronavirus 2 (SARS-CoV-2) in predisposed children. \\ - Clinical presentation of MIS-C involves multiple organ systems, with prominent involvement of the gastrointestinal and cardiovascular systems. \\ - The factors that trigger the development of MIS-C in children exposed to or infected with SARS-CoV-2 are not yet known. \\ - Results from epidemiological, clinical and immunological investigations have revealed that although MIS-C has phenotypic similarities to Kawasaki disease, they are different syndromes. \\ - The approach to treatment of MIS-C aims to mute the augmented inflammatory response.}

most common cause of acquired heart disease in children in the developed world ${ }^{20}$. A diagnostic feature of Kawasaki disease is fever that persists for more than 5 days when untreated. Additional typical clinical features include polymorphic skin rash (erythema), involvement of lips and oral mucosa (lip fissures, strawberry tongue), lymphadenopathy (cervical, often unilateral), non-exudative bilateral conjunctivitis and extremity changes (erythema and oedema of palms and soles that desquamate after 2-3 weeks, usually seen in the subacute phase $)^{20}$.

\begin{abstract}
Aetiology
The aetiology of Kawasaki disease is uncertain, and there is no single specific diagnostic test. The general consensus, based on results from multiple studies, is that Kawasaki disease is an immune-mediated disease triggered by infection (or infections) in patients with a genetic predisposition ${ }^{21-25}$. Some epidemiological features offer clues to the pathogenesis of Kawasaki disease. It is typically noted in children between the ages of 6 months and 5 years, with an estimated incidence of 25 cases per 100,000 children younger than 5 years in North America ${ }^{20,26}$. It is believed that children younger than 6 months, who have immature immune
\end{abstract}

\footnotetext{
Author addresses

${ }^{1}$ Division of Paediatric Cardiology, Children's Hospital of San Antonio/Baylor College of Medicine, San Antonio, TX, USA.

${ }^{2}$ Division of Paediatric Cardiology, The University of Texas Southwestern Medical Center, Dallas, TX, USA.

${ }^{3}$ Service de Rhumatologie Pédiatrique, Centre de Référence des Maladies

Auto-Inflammatoires Rares et des Amyloses, $\mathrm{CHU}$ de Bicêtre, le Kremlin Bicêtre, France.

${ }^{4}$ Division of Paediatrics, Cohen Children's Medical Center, New Hyde Park, NY, USA.

5ivision of Paediatric Cardiology, Driscoll Children's Hospital, Driscoll, TX, USA.

${ }^{6}$ Division of Paediatric Cardiology, Cohen Children's Medical Center, New Hyde Park, NY, USA.

'Division of Paediatric Rheumatology, The Sydney Children's Hospitals Network, Sydney, NSW, Australia.

${ }^{8}$ Division of Neurology, John F Kennedy Medical Center/Hackensack Meridian University, Edison, NJ, USA.

'Division of Pathology and Laboratory Medicine, Northwell Health Laboratories,

Lake Success, NY, USA.

${ }^{10}$ Institut National de la Santé et de la Recherche Médicale, Centre de Recherche des

Cordeliers, Sorbonne Université, Université de Paris, Paris, France.

${ }^{11}$ Department of Biological Sciences \& Engineering, Indian Institute of Technology

Palakkad, Palakkad, India.

${ }^{12}$ These authors contributed equally: Chetan Sharma, Madhusudan Ganigara.
}

systems, are protected by passive immunity provided by the transplacental transfer of maternal antibodies, whereas children older than 5 years have developed protective antibody responses to the ubiquitous antigens that most encounter uneventfully in early childhood ${ }^{27}$. There is a male predominance $(\sim 1.5: 1)$ in the incidence of Kawasaki disease, a feature that is shared by many common childhood infectious diseases ${ }^{28,29}$.

Seasonal variation in the incidence of Kawasaki disease has been noted, with peak incidence occurring in winter and spring in the USA and UK, and in summer in China and Korea ${ }^{30-34}$. Seasonal variation is least evident in Japan, the country with the highest incidence of Kawasaki disease ${ }^{35,36}$. Geographical variation and clustering in the incidence of Kawasaki disease also occurs, with the highest incidence reported in Japan, China, South Korea and Taiwan ${ }^{35,37-39}$. These epidemiological features point towards a transmissible infectious agent, which tends to occur in certain regions of the world with a seasonal variation in its incidence. Evidence exists for the presence of concurrent infections (with bacteria or common respiratory viruses, including coronaviruses) in patients with Kawasaki disease $\mathrm{e}^{40-42}$. Immunohistochemistry analyses have shown infiltration of IgA plasma cells indicative of the antigen-driven immune response in inflamed tissues and the presence of cytoplasmic antigens suggestive of an infectious aetiology in bronchial and vascular endothelial cells and macrophages ${ }^{43}$. However, to date no single organism has been directly proved to cause Kawasaki disease ${ }^{44,45}$.

\section{Involvement of superantigens}

The potential pathogenic role of superantigens has been evaluated, on the basis of observations of preferential expression of T cell receptor (TCR) $\beta$ genes encoding variable regions $\mathrm{V} \beta 2$ and $\mathrm{V} \beta 8.1$ in the peripheral blood lymphocytes of patients with acute Kawasaki disease ${ }^{46-48}$. Superantigen activity has been identified in the gut microbiota of such patients, and culture supernatants of these bacteria contain a heat shock protein (Hsp60, also known as GroEL) that induces T cell division and production of pro-inflammatory cytokines ${ }^{49}$. However, in studies using flow cytometry in large series of patients with Kawasaki disease, TCR skewing and over-presentation of the described TCR clones has not been found, and it is currently believed that Kawasaki disease is a result of $\mathrm{T}$ cell activation by a conventional antigen $^{50,51}$.

\section{Involvement of nutritional disorders}

The role of nutritional disorders, including vitamin $\mathrm{D}$ deficiency, in the pathogenesis of Kawasaki disease is subject to debate ${ }^{52}$. Vitamin D has an anti-inflammatory effect mediated through elevation of expression of IL-10 and inhibition of expression of vascular endothelial growth factor ${ }^{53,54}$. Results from a German population-based study showed that vitamin D supplementation has a protective effect against the development of Kawasaki disease ${ }^{55}$. Low serum concentrations of vitamin D might contribute to the development of coronary artery complications in children with Kawasaki disease ${ }^{56}$. However, other results have 
Table 1 | Comparison of Kawasaki disease and MIS-C

\begin{tabular}{|c|c|c|}
\hline Comparison & Kawasaki disease & MIS-C \\
\hline \multicolumn{3}{|l|}{ Demographics } \\
\hline Age & 6 months to 5 years & $6-11$ years \\
\hline Sex & Male predominance $(\sim 1.5: 1)$ & No apparent predominance \\
\hline $\begin{array}{l}\text { Race or } \\
\text { ethnicity }\end{array}$ & $\begin{array}{l}\text { Highest incidence in Japan, China, } \\
\text { South Korea and Taiwan }\end{array}$ & $\begin{array}{l}\text { Highest incidence in children of } \\
\text { African and Hispanic heritage }\end{array}$ \\
\hline \multicolumn{3}{|l|}{ Pathogenesis } \\
\hline Trigger & $\begin{array}{l}\text { Unknown but some data suggest } \\
\text { possible preceding viral or } \\
\text { bacterial infection }\end{array}$ & $\begin{array}{l}\text { Onset } \sim 3-6 \text { weeks after } \\
\text { SARS-CoV-2 exposure }\end{array}$ \\
\hline \multicolumn{3}{|c|}{ Immunological characteristics } \\
\hline Similarities & \multicolumn{2}{|c|}{ Enhancement of IL- $1 \beta^{+}$neutrophils and immature neutrophils } \\
\hline \multirow[t]{5}{*}{ Differences } & $\begin{array}{l}\text { T cell activation by a conventional } \\
\text { antigen }\end{array}$ & $\begin{array}{l}\text { SARS-CoV-2 viral spike }(\mathrm{S}) \\
\text { protein acts like a superantigen, } \\
\text { triggering a cytokine storm }\end{array}$ \\
\hline & High levels of IL-17 & $\begin{array}{l}\text { High levels of IL-15, IFN } \gamma \text { in } \\
\text { severe cases }\end{array}$ \\
\hline & $\begin{array}{l}\text { Relatively less frequent MAS-like } \\
\text { cytokine profile }\end{array}$ & $\begin{array}{l}>50 \% \text { of patients with MIS-C } \\
\text { have a MAS-like cytokine } \\
\text { phenotype }\end{array}$ \\
\hline & Lymphopenia is rare & Lymphopenia \\
\hline & Anti-SARS-CoV-2 lgG not reported & Anti-SARS-CoV-2 lgG \\
\hline \multicolumn{3}{|c|}{ Clinical features } \\
\hline Similarities & \multicolumn{2}{|c|}{$\begin{array}{l}\text { Similar associations with fever, rash, cervical lymphadenopathy, } \\
\text { neurological symptoms, extremity changes }\end{array}$} \\
\hline Differences & $\begin{array}{l}\text { Relatively high incidence of } \\
\text { conjunctival injection and oral } \\
\text { mucous membrane changes }\end{array}$ & $\begin{array}{l}\text { Relatively high incidence of } \\
\text { gastrointestinal symptoms, } \\
\text { myocarditis and shock, and } \\
\text { coagulopathy }\end{array}$ \\
\hline \multicolumn{3}{|l|}{ Management } \\
\hline Common & $\begin{array}{l}\text { IVIG, glucocorticoids, } \\
\text { acetylsalicylic acid }\end{array}$ & $\begin{array}{l}\text { IVIG, glucocorticoids, } \\
\text { acetylsalicylic acid }\end{array}$ \\
\hline Rare & Infliximab, ciclosporin and anakinra & Anakinra, tocilizumab \\
\hline
\end{tabular}

identified elevation of vitamin D levels during the acute phase of Kawasaki disease in children who subsequently developed coronary arterial lesions $s^{57}$. The contribution of other nutritional factors has also been suggested. For example, iron-deficiency anaemia is associated with development of coronary abnormalities in Kawasaki disease ${ }^{58}$. These varied results suggest the need for further investigation and research to elucidate the role of malnutrition in the pathogenesis of Kawasaki disease.

\section{The role of microbiota}

Disturbances in the normal microbiota (dysbiosis) have been proposed to have a role in the pathogenesis of various autoimmune and inflammatory disorders, including Kawasaki disease ${ }^{59-61}$. Stools from children with Kawasaki disease contain higher numbers of Gram-positive bacteria from the Streptococcus, Staphylococcus, Eubacterium and Peptostreptococcus genera, as well as Hsp60-producing Gram-negative bacteria, and lower numbers of lactobacilli than stools from children with other febrile illnesses or healthy controls ${ }^{49,61,62}$.
Dysbiosis is associated with reduction in the production of short-chain fatty acids (particularly butyrate) and is proposed to lead to aberrant immune responses that are associated with Kawasaki disease ${ }^{63}$.

\section{Genetic susceptibility}

Epidemiological and genetic studies of Kawasaki disease have shed light on the role of genetic susceptibility in its development ${ }^{64}$. Kawasaki disease is prevalent in Japan, but also in children of Japanese ancestry living in Hawaii ${ }^{65}$. Siblings of children with Kawasaki disease have a 10-fold higher risk of development of the condition than children in the general population ${ }^{66}$. Several candidate genes have been identified through genome-wide association studies and linkage studies. The four major groups of genes that have been studied in Kawasaki disease are those associated with T cell activation (ORAI1 and STIM1), B cell signalling (CD40, BLK and $F C G R 2 A$ ), apoptosis (CASP3) and transforming growth factor- $\beta$ (TGF $\beta$ ) signalling (TGFB2, TGFBR2, $M M P$ and $S M A D)^{64}$. CASP3 encodes caspase 3 , which is an effector caspase with a vital role in the execution phase of apoptosis. A single-nucleotide polymorphism in the CASP 3 gene is associated with susceptibility to Kawasaki disease $^{67}$. TGF $\beta$ is another vital protein with a central role in immunoregulation that affects multiple populations of leukocytes. Abnormalities in TGF $\beta$ signalling resulting from genetic variation are involved in Kawasaki disease susceptibility and outcomes ${ }^{68}$. Understanding the roles of these genetic alterations has implications for potential therapeutic approaches ${ }^{69}$. In addition to these groups, mutations in ITPKC, which is involved in $\mathrm{Ca}^{2+}$ mobilization and activation of NLRP3 inflammasomes, could result in enhancement of IL-1 $\beta$ and IL-18 production, disease susceptibility, coronary abnormalities and resistance to treatment with intravenous immunoglobulin (IVIG) ${ }^{70,71}$. Notably, immunosuppressive agents such as ciclosporin, a $\mathrm{T}$ cell inhibitor that blocks the calcineurin-NFAT pathway, have shown promise in the treatment of high-risk IVIG-resistant Kawasaki disease $^{72}$. The observed association of HLA polymorphisms with Kawasaki disease varies; the predominant variant in a Japanese cohort was $H L A-B w 54$, whereas $H L A-B w 51$ was predominantly identified in white and Jewish populations ${ }^{73-75}$. Epigenetic regulation of inflammatory and immunoregulatory genes by factors such as methylation, microRNAs and long noncoding RNAs has been identified in Kawasaki disease, and might be relevant to pathogenesis and prognosis ${ }^{76}$. Additionally, single-nucleotide polymorphisms in cytokine genes, including IL1, KCNN2, TIFAB, P2RY12 and $T N F$, are associated with Kawasaki disease and with risk of coronary artery lesions, as well as IVIG treatment failure $^{77-82}$.

\section{Immunological aberrations}

Innate and adaptive immune responses both have important roles in the development of Kawasaki disease ${ }^{83}$. An intense initial response driven by the innate immune system takes the form of neutrophilic leukocytosis, activation of monocytes, natural killer $(\mathrm{NK})$ cells and $\gamma \delta \mathrm{T}$ cells, and elevation of production of acute-phase 
reactants and cytokines, especially IL- $1 \beta$, which contributes to activation of endothelial cells, inducing upregulation of expression of cell-adhesion molecules, IL6 and IL8 $\left(\mathrm{REFS}^{76-88}\right)$. Pro-inflammatory IL-17 produced by type 17 Thelper $\left(\mathrm{T}_{\mathrm{H}} 17\right)$ cells could activate immune cells such as neutrophils and monocytes, leading to production of other inflammatory cytokines, such as IL-6, TNF and IL-8, thereby contributing to the pathogenesis of many inflammatory disorders ${ }^{89-92}$. By contrast, $\mathrm{CD} 4{ }^{+} \mathrm{CD} 25^{+}$ regulatory $\mathrm{T}\left(\mathrm{T}_{\mathrm{reg}}\right)$ cells contribute to immune tolerance through suppression of the hyperactivation of both innate and adaptive immune cells, via several mutually nonexclusive mechanisms. An imbalance in these pathways could lead to immune dysregulation, which could have a role in the pathogenesis of Kawasaki disease ${ }^{93-96}$.

Neutrophils are activated in Kawasaki disease and release reactive oxygen species, leading to endothelial cell injury ${ }^{83}$. Release of neutrophil extracellular traps (NETs) is also implicated in the pathogenesis of Kawasaki disease ${ }^{97}$. Although NETs have a protective role against infections as components of the innate immune system, they also have pathogenic potential for immune dysregulation and promotion of inflammation and tissue injury ${ }^{98}$. NETs have been implicated in the development and progression of rheumatic diseases, including systemic lupus erythematosus, rheumatoid arthritis and autoimmune vasculitis ${ }^{99-101}$. Yoshida et al. ${ }^{97}$ demonstrated elevation of NET formation in the sera of patients with Kawasaki disease, as well as neutrophil infiltration in the lesions of vasculitis in the coronary arteries and aorta in a mouse model of Kawasaki disease.

Autoimmune antibodies are thought to have a role in the pathogenesis of Kawasaki disease, particularly those against endothelial cell antigens ${ }^{102,103}$. Anti-endothelial cell antibodies could cause endothelial damage, with release of pro-inflammatory cytokines and a hypercoagulable state leading to vessel-wall injury and intravascular thrombosis ${ }^{104}$. However, not all results have demonstrated elevation of anti-endothelial cell antibodies in patients with Kawasaki disease ${ }^{105}$.

Immune complexes might have a role in the development of Kawasaki disease ${ }^{106}$. They appear in the first 7 days of the disease and peak in the second week before declining ${ }^{107}$. Elevation of circulating levels of immune complexes in Kawasaki disease is related to adverse outcomes such as coronary artery abnormalities ${ }^{108,109}$. However, a causal relationship between immune complexes and the pathogenesis of Kawasaki disease has not been definitively established. Activation of the complement system has also been implicated in the pathogenesis of Kawasaki disease, via both the classical and the mannose-binding lectin pathways ${ }^{110,111}$.

Kawasaki disease is considered by some to be a form of IgA vasculitis. In children with Kawasaki disease, intestinal permeability and levels of secretory IgA in the circulation are greater than in unaffected children, and in mouse models of the disease, elevation of levels of circulating secretory $\operatorname{IgA}$ and $\operatorname{IgA}$ deposition in the vasculature are observed ${ }^{112,113}$. Furthermore, pharmacological blockade of zonulin (a modulator of intestinal tight junctions) and administration of IVIG in these mouse models reduce intestinal permeability and cardiovascular inflammation compared with levels in untreated controls ${ }^{114}$.

\section{Therapeutic strategies}

IVIG and acetylsalicylic acid have emerged as first-line therapies for the management of Kawasaki disease ${ }^{20}$. IVIG therapy leads to rapid improvement in the clinical symptoms of rash, fever and conjunctival injection in most patients. Although the exact mechanism of action of IVIG is not yet known, proposals include inhibition of activation of innate immune cells and inflammatory mediators, expansion of $\mathrm{T}_{\text {reg }}$ cells and suppression of $\mathrm{T}_{\mathrm{H}} 17$ cells $^{93,115-118}$. Evidence indicates that IVIG might target IL- $1 \beta^{+}$neutrophils via caspase-independent pathways ${ }^{119}$. Single-cell RNA sequencing of peripheral blood mononuclear cells in acute Kawasaki disease before and after IVIG therapy has revealed that genes encoding inflammatory mediators (including TNF and $I L 1 B$ ) are highly expressed in monocytes in untreated disease, with reduction of expression following therapy, along with significant enhancement of the plasma-cell population and induction of oligoclonal expansion of $\mathrm{T}$ cell receptors and IgG and IgA B cell receptors ${ }^{120}$. Mining of transcriptomic data by Boolean analysis has identified that several metabolic pathways might contribute to IVIG resistance in Kawasaki disease ${ }^{121}$. In high-risk patients with acute Kawasaki disease and in those who do not respond to IVIG therapy, steroid treatment can be considered, to prevent the occurrence of coronary artery abnormalities ${ }^{20}$. Additional therapeutic options for IVIG-resistant Kawasaki disease include infliximab (a monoclonal antibody to TNF), ciclosporin (a calcineurin inhibitor) and anakinra (an IL-1 receptor antagonist $)^{20}$.

\section{Overview of MIS-C}

Since April 2020, many reports have documented a new hyperinflammatory syndrome in children ${ }^{11,12,122}$. In May 2020, the US Centers for Disease Control and Prevention (CDC) issued an alert identifying MIS-C as a critical illness in children that was associated with SARS-CoV-2 infection ${ }^{123}$. Since then, more than 4,000 cases of MIS-C have been reported in the USA alone ${ }^{124}$. In 26 studies published in 2020 and 2021, documenting 1,136 cases of MIS-C (mostly occurring in the USA and Europe), the reported median ages of the affected children were 6-11 years, with no significant gender difference ${ }^{14,15,122,125-140}$ (TABLE 2).

Patients with MIS-C have symptoms that resemble those of other hyperinflammatory syndromes, such as Kawasaki disease, toxic-shock syndrome (TSS) and macrophage activation syndrome (MAS), which is a type of secondary haemophagocytic lymphohistiocytosis ${ }^{11,12}$. To improve clarity and aid diagnosis, the CDC published a case definition, which includes age $<21$ years, fever, laboratory evidence of inflammation, hospital admission, multisystem (two or more) organ involvement (cardiac, renal, respiratory, haematological, gastrointestinal, dermatological or neurological), either laboratory confirmation of SARS-CoV-2 infection (by PCR with reverse transcription (RT-PCR), serology or antigen test) or known COVID-19 exposure up to 4 weeks 
Table 2 | Demographic features of MIS-C study populations

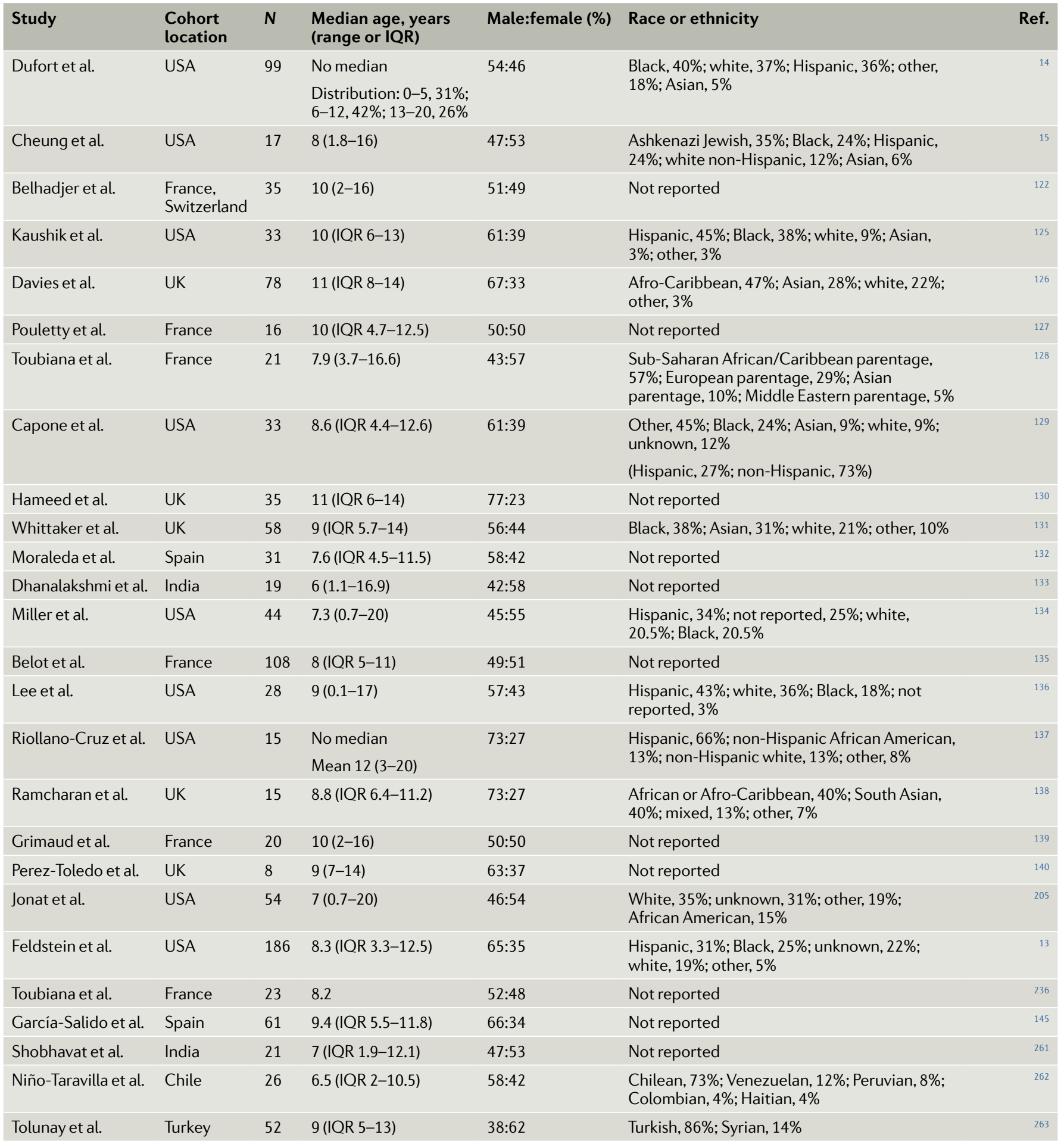

IQR, interquartile range; MIS-C, multisystem inflammatory syndrome in children.

before symptom onset, with no alternative plausible diagnosis $^{123}$. The WHO and the UK Royal College of Paediatrics and Child Health (RCPCH) have also published case definitions, which are largely similar to the CDC definition, except that the RCPCH does not require evidence of prior exposure to SARS-CoV-2 (REFS ${ }^{141,142}$ ). Despite the broad case definitions, and the considerable overlap with primary COVID-19 and other common childhood febrile illnesses, patients with MIS-C have distinct clinical presentation and levels of biomarkers, which aids in differential diagnosis ${ }^{143-145}$.

\section{Aetiology}

Compared with adults, primary SARS-CoV-2 infection is relatively mild in children ${ }^{146}$. Evidence indicates that a temporal relationship exists between SARS-CoV-2 


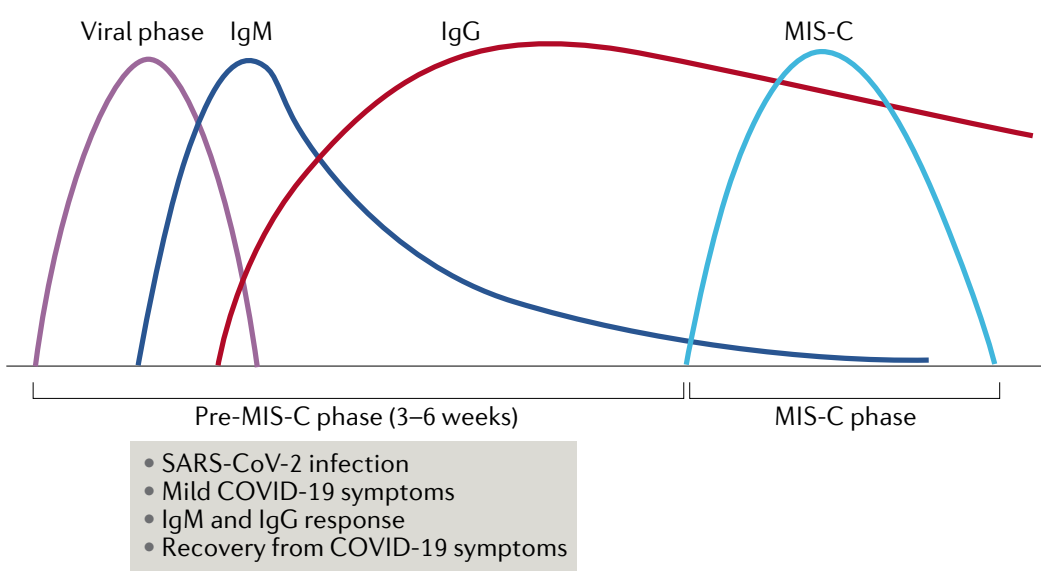

Fig. 1 | The temporal relationship between SARS-CoV-2 infection and development of MIS-C. Evidence suggests that a relationship exists between the timing of severe acute respiratory syndrome coronavirus 2 (SARS-CoV-2) infection and development of multisystem inflammatory syndrome in children (MIS-C). Cases of MIS- $\mathrm{C}$ tend to be seen 3-6 weeks after the peak of SARS-CoV-2 transmission in a community. Because of this time lag, MIS-C is associated with a strong anti-spike protein lgG response, but a weak IgM response. It should be noted that implication of SARS-CoV-2 as a triggering factor for the development of MIS-C has yet to be firmly established.

exposure and development of MIS-C, as a spike in MIS-C cases occurs 3-6 weeks after the peak of SARS-CoV-2 transmission in a community ${ }^{13,129,147}$ (FIG. 1). Median intervals of 21 and 25 days have been observed between the occurrence of COVID-19 symptoms and the onset of MIS-C ${ }^{13,14}$. Although $80-90 \%$ of patients with MIS-C have been found to be SARS-CoV-2 seropositive, positivity in PCR testing is only $20-40 \%$, suggesting that the interval to the onset of MIS-C is sufficient for viral RNA levels to fall considerably ${ }^{148,149}$. Furthermore, nasopharyngeal aspirates from patients with MIS-C have higher SARS-CoV-2 real-time RT-PCR cycle thresholds (indicating lower levels of viral RNA) than those from patients with severe COVID-19 (REF. ${ }^{150}$ ). However, autopsy examinations for three individuals who had MIS-C identified SARS-CoV-2 in various tissues, including heart, kidneys, brain and intestine, which is consistent with multisystem organ involvement in MIS-C ${ }^{151}$. Notably, the prolonged presence of SARS-CoV-2 in children's intestines might cause zonulin-dependent loss of tight junctions, leading to leakage of viral antigens into the circulation, and to hyperinflammation and MIS- $\mathrm{C}^{152}$. By contrast, single-cell RNA sequencing of peripheral blood mononuclear cells from patients with acute MIS-C have revealed low viral and bacterial signatures in the immune cells, suggesting that active viral or bacterial infectious triggers are not contributing factors ${ }^{153}$. The accumulated evidence suggests that MIS-C might be the result of a combination of post-infectious immune dysregulation and virus-induced cytopathic effects and inflammation in multiple organ systems.

Paediatric patients with COVID-19 or MIS-C have strong IgG, but weak IgM antibody responses to the trimeric $\mathrm{S}$ glycoprotein of SARS-CoV-2, and weak responses to the nucleocapsid protein $\mathrm{N}$, which is implicated in viral replication ${ }^{140,154-158}$. By contrast, adult COVID-19 patients have higher levels of anti-S antibodies, broader immunoglobulin response to
SARS-CoV-2 with respect to specificity and isotype distribution (including IgG, IgM and IgA isotypes) and higher virus-neutralizing capacity ${ }^{140,155,156,158}$. The mild or asymptomatic nature of COVID-19 in children might be related to the extent of the antibody response. Nevertheless, IgG antibodies to $S$ protein provide an important diagnostic criterion for MIS-C. Low IgM titres in MIS-C are consistent with its appearance several weeks after SARS-CoV-2 exposure.

Analyses from geographically diverse cohorts have demonstrated that $20-50 \%$ of people with no previous exposure to the virus have $\mathrm{T}$ cell reactivity against peptides corresponding to SARS-CoV-2 sequences ${ }^{159}$, which might be related to $\mathrm{CD} 4^{+} \mathrm{T}$ cell cross-reactivity with circulating seasonal human 'common cold' coronavirus $(\mathrm{HCoV})^{160}$. Although this phenomenon has implications for the development of herd-immunity models and vaccine candidates, it is currently unclear whether the presence of prior cross-reactive $\mathrm{CD} 4^{+} \mathrm{T}$ cells is protective or harmful in the pathogenesis of MIS-C. When tested for serological evidence of prior seasonal coronavirus infection, children with MIS-C and those hospitalized for non-COVID reasons had similar prevalence and levels of antibodies to $\mathrm{HCoV}^{161}$. Additionally, $\mathrm{HCoV}$ antibody levels did not correlate with the levels of SARS-CoV-2 antibodies, suggesting that prior $\mathrm{HCoV}$ infection neither provides protection nor worsens the course of paediatric SARS-CoV-2 infection or MIS-C.

\section{SARS-CoV-2 $S$ protein as a superantigen}

SARS-CoV-2 viral $\mathrm{S}$ protein might behave like a superantigen, triggering a cytokine storm that results in the development of the TSS-like presentation of MIS- $\mathrm{C}^{162}$ (FIG. 2). The $S$ protein has a high-affinity motif for binding TCR, which is similar in structure to the staphylococcal enterotoxin B, a superantigen that mediates TSS by interacting with both TCR and MHC class II molecules. Computational modelling has shown that SARS-CoV-2 encodes a superantigen motif near the S1/S2 cleavage site, which interacts with both the TCR and CD28 (REF. ${ }^{163}$ ). TCR repertoire analysis of T cells in a small number of patients with MIS-C has identified skewing of TCR V $\beta$ towards TRBV11-2 (Vß21.3), which is associated with HLA class I alleles A02, B35 and C04 (REFS ${ }^{163,164}$ ). The CDR3-independent nature of TCR V $\beta$ skewing suggested superantigen-mediated activation of T cells in MIS-C. Further evidence supports the enrichment of TRBV11-2 among $\mathrm{T}$ cells ${ }^{153,165}$, although notably it has been observed in the absence of differential expression of a set of 'superantigen genes ${ }^{\prime 153}$. Also, MIS-C is usually observed several weeks after primary SARS-CoV-2 exposure, in contrast to the acute illness and cytokine storm observed in TSS ${ }^{166}$. In most cases, SARS-CoV-2 is undetectable in patients with MIS-C during the acute phase of inflammation. Thus, the superantigenic property of SARS-CoV-2 S protein and its implication in MIS-C is not yet confirmed. As an RNA virus, SARS-CoV-2 undergoes constant mutation, and whether any particular variant of the virus contributes to MIS-C by triggering strong inflammatory signalling in the immune cells and endothelial cells of children with COVID-19 requires further exploration. Notably, the use of in silico techniques has demonstrated 
that mutations in the binding region of SARS-CoV-2 S protein could influence the interaction with MHC class II molecules and $\mathrm{TCR}^{163}$.

\section{Involvement of nutritional disorders}

Nutritional factors such as vitamin D deficiency might have a role in the development of MIS-C. Adults with vitamin $\mathrm{D}$ deficiency were noted to have a more severe form of COVID-19 with an increased risk of death than those without this deficiency ${ }^{167}$. Vitamin D supplementation has proved to be of some benefit in infections with other viruses, such as influenza $\mathrm{A}^{168}$. Whether a similar benefit could accrue in MIS-C has not been elucidated.

\section{The role of microbiota}

Another contributing factor in the development of MIS-C that warrants investigation is the role of gut and respiratory tract microbiota. Gastrointestinal microbes are important regulators of the gut immune system and inflammation, and influence the balance between $\mathrm{T}_{\mathrm{H}} 17$ cells and $\mathrm{T}_{\text {reg }}$ cells ${ }^{169}$. Adult patients with COVID-19 display alteration of gut and upper respiratory microbiomes, and gut dysbiosis persists beyond the nasal clearance of SARS-CoV-2 (REFS ${ }^{170-173}$ ). Notably, faecal SARS-CoV-2 load is inversely correlated with the abundance of bacteria of the Bacteroidetes phylum, which suppress ACE2 in the mouse gut ${ }^{173}$. Preliminary data

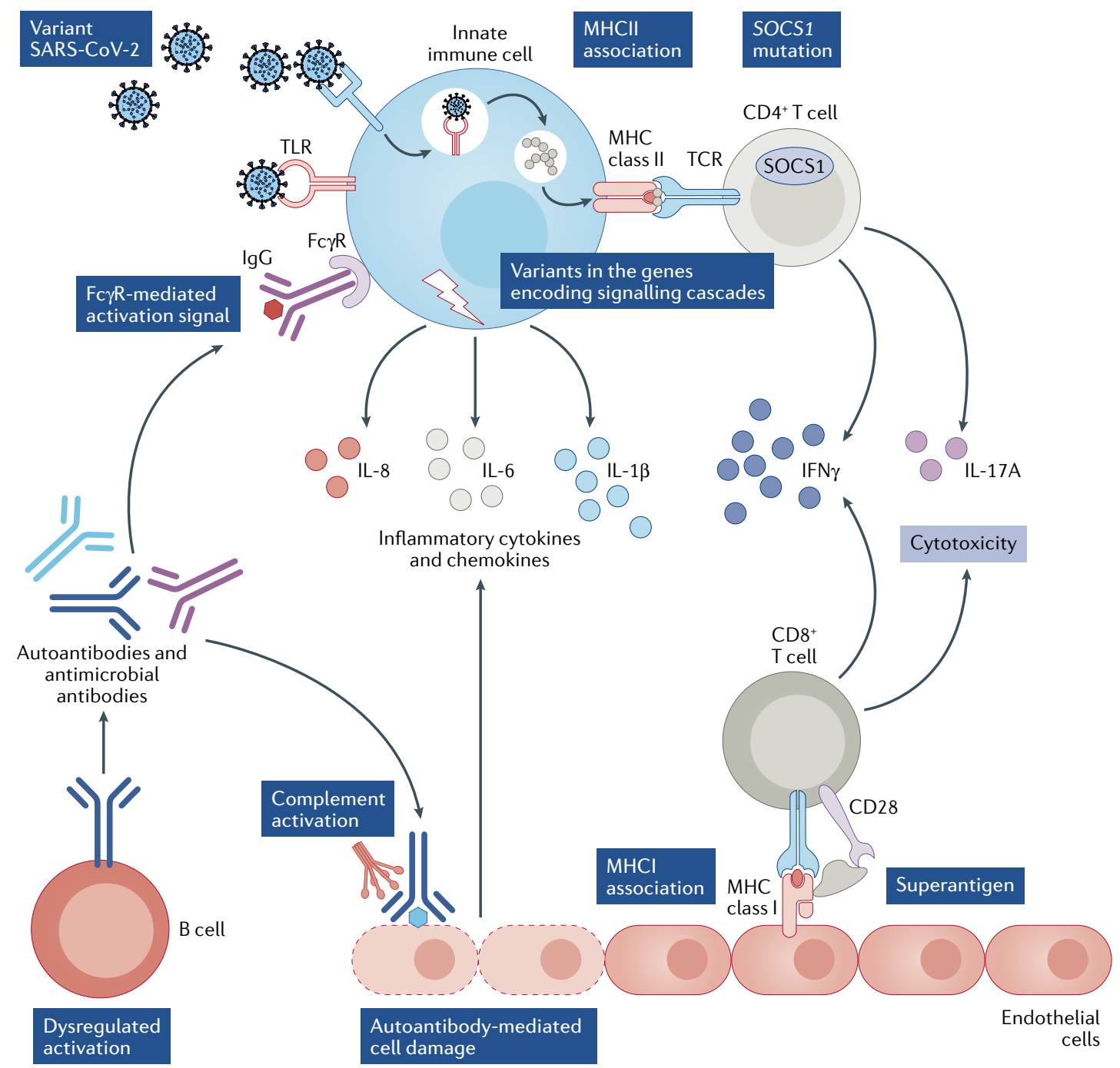

Fig. 2 | Possible mechanisms implicated in aberrant activation of immune cells in MIS-C. Clinical signs of multisystem inflammatory syndrome in children (MIS-C) mostly appear several weeks after severe acute respiratory syndrome coronavirus 2 (SARS-CoV-2) infection. MIS-C might be triggered by dysregulation of immune responses following viral infection. Aberrant activation of immune cells in patients with MIS-C could result from several factors. Infection with particular variants of SARS-CoV-2 might trigger hyperinflammatory responses. Genetic predisposition resulting from variants in the genes that encode pattern recognition receptors, Fc $\gamma$ receptors and components of the signalling cascades of immune response, as well as mutations in genes such as SOCS1, which regulate inflammatory responses, could all contribute to enhancement of inflammatory responses to infection. Dysregulated activation of lymphocytes, with production of lgG corresponding to microbial pathogens or autoantigens, could cause immune-complex-mediated innate-cell activation by signalling via $\mathrm{F} c \gamma$ receptors. Production of autoantibodies could also lead to complement activation and autoantibody-mediated endothelial damage. SARS-CoV-2 spike (S) protein might function as a superantigen, contributing to activation of T cells. SOCS1, suppressor of cytokine signalling 1; TLR, Toll-like receptor. 
from peer reviewed and non-peer reviewed reports also suggest the persistence of microbiome dysbiosis in the upper respiratory tract and the gut in paediatric COVID-19 (REFS ${ }^{174,175}$ ).

\section{Genetic susceptibility}

The low incidence of MIS-C relative to COVID-19, and the similarity in antibody response to SARS-CoV-2 in paediatric patients with MIS-C and with COVID-19 (irrespective of the subsequent development of MIS-C) suggest that SARS-CoV-2 infection causes dysregulation of immune responses in a subgroup of predisposed children with particular genetic backgrounds ${ }^{176}$. Specifically, predisposition might be related to mutations and polymorphisms in the genes that encode pattern recognition molecules such as Toll-like receptors, components of the signalling cascades of the immune response and $\mathrm{Fc} \gamma$ receptors (FIG. 2). The incidence of MIS-C is higher in children of African and Hispanic heritage than in those of other ethnicities, although attribution of this finding to genetic differences is confounded by the contribution of socioeconomic factors to the risks of SARS-CoV-2 infection ${ }^{177-180}$. Among 145 HLA-A, HLA-B and HLA-C genotypes, $H L A-B^{\star} 46: 01$ was associated with in silico prediction of the fewest SARS-CoV-2-binding peptides (suggesting particular vulnerability to COVID-19), whereas $H L A-B^{*} 15: 03$ was predicted to have the greatest capacity for coronavirus peptide presentation (suggesting protective T cell-based immunity ${ }^{181}$. Monogenic loss-of-function variants affecting immunity in the type I interferon signalling pathway might confer a predisposition to severe COVID-19 manifestations ${ }^{182,183}$. In a study of two unrelated patients with infection-associated immune thrombocytopenia and autoimmune haemolytic anaemia, both had SOCS1 haploinsufficiency and exhibited $\mathrm{T}$ cell activation and high levels of interferon signalling, and one developed MIS-C after SARS-CoV-2 infection. SOCS are negative regulators of interferon signalling, and silencing mutations might predispose the individuals to infection-associated hyperinflammatory states such as MIS-C ${ }^{184}$ (FIG. 2). However, a clear genetic basis that explains why some children develop MIS-C after SARS-CoV-2 exposure is currently undetermined. Additional factors, such as epigenetic effects at the level of histones, DNA or microRNA might also contribute to the development of MIS-C.

\section{Immunological aberrations}

In general, the signatures of immune cells and inflammatory parameters of MIS-C closely overlap with those of adults with moderate-to-severe COVID-19 rather than with paediatric COVID-19, which is mostly mild or asymptomatic. Also, immune activation in MIS-C is transient and tends to reduce during recovery ${ }^{154,185,186}$.

Pro-inflammatory mediators. Elevation of levels of pro-inflammatory cytokines such as IL-6, IL-10 and IL-17A, and chemokines such as CXCL5, CXCL11, CXCL1 and CXCL6 in MIS-C distinguishes it from paediatric COVID-19 (REFS ${ }^{136,153,154,187}$ ). In various cohorts, elevation of TNF, IL-1 $\beta$, IFN $\gamma$, soluble IL-2R, CCL2, CCL3, CCL4, CXCL8 (IL-8) or IFN $\gamma$-induced chemokines CXCL9 and CXCL10 has been reported in the serum of patients with MIS-C relative to those with paediatric COVID-19 or healthy controls ${ }^{136,150,153,165,186-189}$. Overall, enhancement of these pro-inflammatory molecules in the circulation indicates inflammatory responses of myeloid and lymphoid cells. Endothelial cells could also contribute innate inflammatory mediators, as E-selectin, a marker of inflamed endothelial cells, shows elevation in the serum of patients with MIS- $\mathrm{C}^{153}$. The reasons for the absence of some pro-inflammatory mediators in particular cohorts of patients are not known. The mediators that were analysed could have differed from study to study, but also, the levels of inflammatory mediators might vary depending on the patients' genetic and epigenetic backgrounds, severity of the disease, geographical location and timing of the analyses. Results from a study of plasma proteomics in children with SARS-CoV-2 infection, which have not yet undergone peer review, suggest that IFN $\gamma$ expression is heterogeneous among patients with MIS-C, and that patients have dysregulated response to IFN $\gamma^{190}$. As the pandemic progresses, it will be important to have a consensus regarding the panel of cytokines and chemokines that should be analysed in relation to MIS-C, to facilitate our understanding of the molecular pathogenesis and heterogeneity of this complex disease, and to enable accurate prognosis and effective treatment.

Immune-cell profiles. Immune-cell profiling of children with MIS-C or primary COVID-19 infection reveals similarities as well as differences in their immune signatures ${ }^{185}$. They have similar proportions of eosinophils, immature granulocytes, monocytes and classic dendritic cells, but patients with MIS-C have elevation of neutrophils and reduction of plasmacytoid dendritic cells ${ }^{153,185,188}$, which might contribute to the low levels of IFNa that are observed in the blood of patients with MIS-C relative to those with paediatric COVID-19 (REF. ${ }^{188}$ ).

Neutrophils and monocytes are activated in patients with MIS-C ${ }^{186}$ and show upregulation of alarmin signatures (in particular S100A genes) and reduction of expression of antigen-presenting, antigen-processing and co-stimulatory molecules ${ }^{153,165,186}$. Compared with healthy children, those with MIS-C have greater expression of cytotoxicity genes and CCL4 in NK cells, which might contribute to the occurrence of tissue damage ${ }^{153}$. Preliminary results suggest that plasma levels of IFN $\gamma$ correlate with levels of NCR1 and IL-2RA, which are the soluble markers of activated NK and T cells, respectively ${ }^{190}$.

MIS- $C$ could have a common pathophysiology with Kawasaki disease involving NET formation, which has been described in the sera of adults with COVID-19 and with endothelial injuries or a prothrombotic state $^{191-193}$. However, plasma levels of NETs and release of NETs from neutrophils are similar in children with mild or moderate COVID-19 or MIS-C and in healthy children ${ }^{194}$. Despite similarities between disorders associated with pathogenic NETs and MIS-C, the role of NETosis in the pathogenesis of MIS-C remains uncertain because of a lack of definitive evidence, and hence further studies are warranted. 
Both MIS-C and paediatric COVID-19 present with general lymphopenia (affecting cells that include mucosa-associated invariant T cells, $\gamma \delta \mathrm{T}$ lymphocytes and CD8 ${ }^{+} \mathrm{T}$ lymphocytes) $)^{136,150,154,185-188}$. Compared with paediatric COVID-19, in MIS-C there is more-pronounced $\mathrm{CD} 4^{+} \mathrm{T}$ cell-biased lymphopenia, which is similar to the situation in severely ill adults with COVID-19 (REF. ${ }^{185}$ ). However, results from single-cell RNA sequencing analysis have revealed enhanced proliferation of $\mathrm{CD} 4^{+} \mathrm{T}$ cells in patients with MIS-C compared with healthy individuals ${ }^{153}$, suggesting that lymphopenia might be the result of homing of T cells to the inflamed tissues. Despite showing T cell lymphopenia, the relative distribution of various $\mathrm{T}$ cell subsets such as naive, central memory and effector memory cells in patients with MIS-C is similar to that in age-matched healthy individuals, indicating a pan-CD $4^{+} / \mathrm{CD}^{+} \mathrm{T}$ cell lymphopenia, rather than a subset-specific effect ${ }^{154,185}$.

A distinct feature of MIS-C compared with paediatric COVID-19 is the activation of $\mathrm{CX}_{3} \mathrm{CR} 1^{+} \mathrm{CD} 8^{+} \mathrm{T}$ cells $\left(\mathrm{CD}^{+} \mathrm{T}\right.$ cells that express vascular endothelium-homing $\mathrm{CX}_{3} \mathrm{CR} 1$, also known as fractalkine receptor), which could have implications for development of vascular abnormalities and cardiovascular abnormalities ${ }^{185}$. This immunological phenotype is correlated with elevation of D-dimer, reduction of platelets and with the requirement for vasoactive medication. Although not as prominent as in NK cells, $\mathrm{CD}^{+} \mathrm{T}$ cells in MIS-C also show increases in signatures of cytotoxicity compared with those in healthy children ${ }^{153}$. RNA sequencing in blood from children with MIS-C revealed aberrant $\mathrm{NK}$ and $\mathrm{CD} 8^{+} \mathrm{T}$ cell regulation, with depletion of NK cells and an absence of NK cell-dependent exhaustion of effector $\mathrm{CD}^{+} \mathrm{T}$ cells, which can lead to sustained inflammation ${ }^{195}$. Notably, the proportion of activated $\mathrm{CX}_{3} \mathrm{CR} 1^{+} \mathrm{CD} 8^{+} \mathrm{T}$ cells in patients with MIS-C decreases as the clinical status improves ${ }^{185}$. Thus, there seems to be a sustained activation and dysregulation of $\mathrm{CD}^{+} \mathrm{T}$ cells, particularly those that express $\mathrm{CX}_{3} \mathrm{CR} 1$.

Nonspecific activation of $\mathrm{B}$ cell clones and expansion of plasmablasts occurs in MIS-C ${ }^{150,153,185,186}$. Plasmablast elevation also occurs in children with COVID-19 (REF. ${ }^{185}$ ). However, the specificity of expanded B cells and plasmablasts might vary between the two conditions. Patients with MIS-C display pronounced autoreactivity signatures of plasma immunoglobulins compared with healthy children or adults and children with COVID-19 $\left(\right.$ REFS $\left.^{103,153,154}\right)$. Also, patients with MIS-C have evidence of extrafollicular responses, as indicated by high frequencies of plasmablasts expressing the $\mathrm{T}$ box transcription factor T-bet ${ }^{185}$. Future research should aim to uncover the reasons for this $\mathrm{B}$ cell activation, and should compare the characteristics of expanded B cells and plasmablasts, and the specificities of immunoglobulins, in MIS-C and paediatric COVID-19. As both conditions are associated with nonspecific $\mathrm{B}$ cell activation and elevation of plasmablast frequencies ${ }^{196}$, molecular mimicry between self-antigens and SARS-CoV-2 antigens (as described in a paper that has not yet been peer reviewed ${ }^{197}$ ) might not be entirely responsible for the appearance of autoreactivity in MIS-C, and instead a combination of molecular mimicry and dysfunctional immunoregulatory machinery could be involved.
Humoral features. Analysis of IgG by systems serology has identified that humoral features in patients with MIS-C, such as complement deposition and neutrophil phagocytosis, overlap with those in convalescent adults with COVID-19 (REF. ${ }^{158}$ ). However, patients with severe MIS-C have persistent levels of $\mathrm{Fc} \gamma \mathrm{R}$ binding (and in particular activating Fc $\gamma$ RIIA) and inflammatory monocyte/macrophage-activating $\operatorname{IgG}^{158}$. Although hypergammaglobulinaemia is not observed in patients with MIS-C, a selective expansion of the IgG repertoire to react not only to SARS-CoV-2, but also to other bacterial and viral pathogens, some of which are implicated in the triggering of Kawasaki disease, has been observed. The underlying reason for the enrichment of particular IgG specificities is not yet known, but many of the microbes have been identified in the respiratory tracts of patients with MIS-C ${ }^{198}$, suggesting a role for an immune-complex-driven inflammatory response in the pathogenesis of MIS-C. IgG and IgA autoantibodies occur in patients with MIS-C, and recognize gastrointestinal, mucosal, immune-cell and endothelial antigens ${ }^{153,154}$. Although the functionality of these autoantibodies and their roles in the pathogenesis of MIS-C should be investigated, these results might explain at least in part the involvement of multiple organ systems in MIS-C and provide a pointer towards dysregulated activation of B lymphocytes, enhanced autoreactivity and immune-complex-mediated inflammatory responses (FIG. 2). Enhanced expression of CD64 $(\mathrm{F} c \gamma \mathrm{R} 1)$, a high-affinity receptor for the Fc fragment of IgG, has been observed on neutrophils and monocytes of patients with MIS-C $\mathrm{C}^{154,186}$. Furthermore, most of these patients respond to IVIG therapy ${ }^{11,15,122,129,131}$, which provides additional indirect support for the implication of Fc $\gamma$ R-mediated activation of innate immune cells by immune complexes formed by these IgGs.

A role for the complement system in the pathogenesis of MIS-C has been suggested. Patients with MIS-C or paediatric COVID-19 have elevated plasma levels of soluble C5b-9 compared with healthy controls ${ }^{150,199}$. Soluble C5b-9 is a biomarker to monitor the activity of the terminal pathway of complement, and elevated levels suggest complement activation and endothelial dysfunction. Notably, although patients with MIS-C and paediatric COVID-19 have similar levels of complement-activating IgG antibodies to S protein of SARS-CoV-2 (REFS ${ }^{140,154-158}$ ), those with MIS-C have enhanced autoreactive signatures of $\operatorname{IgG}^{103,153,154}$. As patients with MIS-C typically have minimal or no SARS-CoV-2 at the time of development of the disease, enhanced autoreactivity and immune-complex formation might contribute to the elevated levels of C5b-9. Consistent with complement activation, MIS-C is associated with clinical criteria for complement-mediated thrombotic microangiopathy, such as microangiopathic haemolytic anaemia, hypertension, thrombocytopenia, proteinuria and evidence of organ damage on the basis of lactate dehydrogenase elevation ${ }^{199}$. Compared with paediatric COVID-19, patients with MIS-C have higher incidence of thrombotic events ${ }^{200}$. Results from proteomics analyses of plasma samples, which have not yet been peer reviewed, suggest that phospholipase A2 (PLA2G2A) could be a biomarker for diagnosis of thrombotic 
microangiopathy in MIS- $\mathrm{C}^{190}$. The lectin complement pathway might also have an important role in the pathogenesis of diseases associated with SARS-CoV-2, as a result of the carbohydrate-residue-rich surface structures of the virus ${ }^{201-203}$.

\section{Therapeutic strategies}

Treatment approaches to MIS-C aim to mute the exaggerated inflammatory response. Multiple approaches, borrowed from Kawasaki disease and other hyperinflammatory syndromes, have been considered, ranging from IVIG to glucocorticoids and immunotherapy ${ }^{204,205}$. MIS-C treatment regimens described in 24 studies, involving 1,020 individuals, are summarized in TABLE 3, highlighting the many variations on the theme of attempting to calm overactive inflammatory responses ${ }^{6,17,20,94,100-114,164}$. In most studies, most $(70-100 \%)$ of the patients were treated with IVIG as the first-line agent, with satisfactory results. Steroids were the second most common treatment employed for patients with MIS-C.

Shock and cardiovascular manifestations comprise a predominant mode of presentation of MIS-C, and high-dose glucocorticoids have been advocated for, and used successfully in, patients with shock. Widely followed guidance from the ACR recommends IVIG as first-line therapy in hospitalized patients with MIS-C, with addition of glucocorticoids in the presence of shock, organ-threatening disease or refractory disease ${ }^{149}$. In a study of 181 children with suspected MIS-C, IVIG alone had a higher failure rate than the use of IVIG with methylprednisolone (OR 0.25; 95\% CI 0.09-0.70) ${ }^{206}$. By contrast, results from a multinational observational cohort study that involved 615 children with suspected MIS-C identified no difference in acute outcomes between primary treatment with IVIG alone, IVIG with steroids or steroids alone ${ }^{207}$. In view of the apparently important role of IL- $1 \beta$ in the pathogenesis of MIS-C, anakinra (an IL-1 receptor antagonist) has been used in MIS-C that is refractory to therapy with IVIG or steroids, extrapolating from its success in small groups of patients with IVIG-resistant Kawasaki disease ${ }^{122,148,208,209}$.

Zonulin-dependent loss of intestinal mucosal permeability is implicated in mediation of the hyperinflammation observed in MIS-C, and accordingly, a patient who did not respond to anti-inflammatory therapies

Table 3 | Treatment of MIS-C

\begin{tabular}{|c|c|c|c|c|c|c|}
\hline Study & $\begin{array}{l}\text { Cohort } \\
\text { location }\end{array}$ & $N$ & IVIG (\%) & $\begin{array}{l}\text { Glucocorticoids } \\
\text { (\%) }\end{array}$ & Other treatments & Ref. \\
\hline Dufort et al. & USA & 99 & 70 & 64 & NR & 14 \\
\hline Cheung et al. & USA & 17 & 77 & 82 & Tocilizumab, 6\% & 15 \\
\hline Belhadjer et al. & $\begin{array}{l}\text { France, } \\
\text { Switzerland }\end{array}$ & 35 & 72 & 34 & Anakinra, $9 \%$ & 122 \\
\hline Kaushik et al. & USA & 33 & 54 & 51 & $\begin{array}{l}\text { Tocilizumab, } 36 \% \text {; remdesivir, } 21 \% \text {; anakinra, } 12 \% \text {; } \\
\text { convalescent plasma therapy, } 3 \%\end{array}$ & 125 \\
\hline Pouletty et al. & France & 16 & 94 & 18.8 & Tocilizumab, 6\%; anakinra, 6\%; hydroxychloroquine, $6 \%$ & 127 \\
\hline Toubiana et al. & France & 21 & 100 & 33 & NR & 128 \\
\hline Capone et al. & USA & 33 & 100 & 70 & Tocilizumab, $9 \%$; anakinra, $12 \%$; infliximab, 3\% & 129 \\
\hline Dhanalakshmi et al. & India & 19 & 79 & 58 & Tocilizumab, 5\% & 133 \\
\hline Miller et al. & USA & 44 & 82 & 96 & Anakinra, $18 \%$ & 134 \\
\hline Lee et al. & USA & 28 & 71 & 61 & Anakinra, $18 \%$ & 136 \\
\hline Riollano-Cruz et al. & USA & 15 & 80 & 20 & $\begin{array}{l}\text { Tocilizumab, } 80 \% \text {; remdesivir, } 13 \% \text {; anakinra, } 13 \% \text {; } \\
\text { convalescent plasma therapy, } 6 \%\end{array}$ & 137 \\
\hline Ramcharan et al. & UK & 15 & 66 & 33 & NR & 138 \\
\hline Grimaud et al. & France & 20 & 100 & 10 & Tocilizumab, $10 \%$; anakinra, $10 \%$ & 139 \\
\hline Jonat et al. & USA & 54 & 83 & 79 & NR & 205 \\
\hline Feldstein et al. & USA & 186 & 77 & 49 & Anakinra, 13\% & 13 \\
\hline Toubiana et al. & France & 23 & 100 & 61 & NR & 236 \\
\hline
\end{tabular}

IVIG, intravenous immunoglobulin; MIS-C, multisystem inflammatory syndrome in children; NR, not reported. 
was treated with the zonulin antagonist larazotide, with a satisfactory outcome ${ }^{152}$. In a pooled meta-analysis, $\mathrm{D}$-dimer was found to be elevated in $92 \%$ of patients (330 out of 356 $)^{210}$. Because of the associated risk of hypercoagulability, and extrapolating from the management of Kawasaki disease, the use of anticoagulants such as acetylsalicylic acid and/or enoxaparin has been reported $^{211,212}$.

\section{MIS-C: distinct from Kawasaki disease?}

Both Kawasaki disease and MIS-C have temporal associations with infectious diseases and are associated with immune-system alteration, systemic inflammation and cytokine storm. Myocardial dysfunction, which is seen in both pathologies, might be a consequence of systemic inflammation ${ }^{213,214}$. An artificial intelligence computational analysis based on viral pandemics and disease-severity gene signatures, and in particular induction of IL15-IL15RA genes, has placed Kawasaki disease and MIS-C on the same host-immune-response continuum (although these results have not yet been peer reviewed $)^{215}$. Consistently, patients with MIS-C have significantly higher levels of IL-15 than paediatric patients with COVID-19 (REF $\left.{ }^{189}\right)$. However, the intensity of the immune response is high in MIS-C, which places it further along the severity spectrum than Kawasaki disease ${ }^{215}$.

A quarter to half of patients with MIS-C meet the full criteria for diagnosis of Kawasaki disease $\mathrm{e}^{17,148,149,212,216}$. Without evidence of prior SARS-CoV-2 exposure in these patients, it might not be possible to differentiate them from those with classic Kawasaki disease. Commonly reported clinical features of MIS-C include fever, mucocutaneous findings, myocardial dysfunction with cardiogenic or vasoplegic shock, gastrointestinal symptoms and neurological features including headache and altered mental status (TABLE 4). Like Kawasaki disease, these clinical manifestations are not specific to MIS-C, and they could occur in other infectious or inflammatory conditions ${ }^{20}$.

\section{Epidemiological and clinical differences}

Despite the apparent similarities between MIS-C and Kawasaki disease, there are important epidemiological and clinical differences ${ }^{20,122,127}$. Kawasaki disease is typically a disease of young children $<5$ years old, whereas MIS-C has been reported in a wide age range from 1.6 to 20 years, with a median age of 6-11 years ${ }^{20,217,218}$ (TABLE 2). In sharp contrast to Kawasaki disease, there is a surprising lack of reports of MIS-C from Japan and East Asian countries $^{219,220}$. In fact, published data from the USA and Europe suggest that MIS-C is most commonly encountered in children of African and Hispanic heritage $\mathrm{e}^{177,180}$. These epidemiological differences suggest that although MIS-C has phenotypic similarities to Kawasaki disease, they are essentially distinct syndromes.

Cardiac involvement is more prevalent and severe in MIS-C than in Kawasaki disease. Although a quarter of untreated patients with Kawasaki disease will develop coronary artery abnormalities, in the current era with a high level of clinical suspicion as well as early diagnosis and treatment, the incidence of coronary artery abnormalities in Kawasaki disease is $<10 \%^{216,221-224}$. By contrast, our understanding of coronary artery dilation in MIS-C is still evolving, and incidence rates of $14-48 \%$ have been reported in various patient populations ${ }^{180,191,192}$ (FIG. 3). However, the adoption of standardized MIS-C management protocols has begun to reduce the rate of coronary artery involvement ${ }^{149}$. Cardiac MRI in MIS-C has demonstrated high signal intensity on T1-weighted and T2-weighted imaging, consistent with diffuse myocardial oedema, with no enhancement on late gadolinium imaging to suggest fibrosis ${ }^{225}$. Results from echocardiographic studies have demonstrated that global left ventricular longitudinal strain is significantly lower in individuals with MIS-C than in those with Kawasaki disease ${ }^{226}$. A longitudinal, single-centre study involving 15 children with MIS-C has demonstrated significant improvement towards normalization of both ventricular function and coronary artery size over a 30-day follow-up period ${ }^{227}$.

Fewer than $10 \%$ of cases of Kawasaki disease manifest as Kawasaki disease-shock syndrome (KDSS), which requires the use of intravascular fluid resuscitation and vasoactive medication ${ }^{228-231}$. Patients with KDSS tend to be older, have longer duration of fever and higher levels of inflammatory markers, and have a higher incidence of IVIG resistance as well as coronary abnormalities than those without KDSS ${ }^{232,233}$. By contrast, shock and depressed left ventricular systolic function are more frequent with MIS-C, for which reports indicate that $40-80 \%$ of patients present with shock ${ }^{210,234-236}$ (FIC. 3). In a retrospective comparison of a cohort of patients with KDSS with published data relating to MIS-C, individuals with KDSS were more likely than those with MIS-C to fulfil the diagnostic criteria for complete Kawasaki disease, with higher incidence of coronary artery aneurysms ${ }^{237}$.

Kawasaki disease has been reported to occur with $\mathrm{MAS}^{238,239}$. In a retrospective analysis of 638 patients with Kawasaki disease, the incidence of MAS was $<2 \%{ }^{240}$. However, this figure is likely to be an underestimation of the true incidence, as a result of an absence of sensitive diagnostic criteria and a lack of awareness among health-care providers ${ }^{241}$. Patients with Kawasaki disease and MAS tend to have elevation of levels of IFN $\gamma$, TNF, serum neopterin, IL-18 and sTNFR-II ${ }^{242}$. A retrospective comparison of patients with MAS (as a complication of systemic-onset juvenile idiopathic arthritis) and MIS-C revealed that MAS was associated with lower levels of haemoglobin and fibrinogen, and higher ferritin and lactate dehydrogenase, whereas patients with MIS-C tended to have signs of shock and need of intensive care management ${ }^{243}$. Results that have not yet been peer reviewed, based on analyses of IFN $\gamma$ and CXCL9 signalling characteristics, suggest that $>50 \%$ of patients with MIS-C have a MAS-like cytokine phenotype ${ }^{190}$, along with elevation of CD163, IL-2RA and ferritin (during the early period) in the plasma. However, although MAS has an association with neutropenia, patients with MIS-C, including those who meet the criteria for MAS, display neutrophilia. Thus, although KDSS and Kawasaki disease with MAS have overlapping clinical features with MIS-C, there are subtle differences that are likely to reflect the different cytokine profiles in these conditions. 
Gastrointestinal and neurological symptoms are also more commonly encountered in MIS-C than in Kawasaki disease $\mathrm{e}^{134,235,236,244-247}$. The gastrointestinal manifestations include abdominal pain, vomiting and diarrhoea ${ }^{210,235,246}$, with rare presentations that resemble appendicitis requiring surgical exploration ${ }^{248}$. In a national US registry consisting of 1,695 children and adolescents with active COVID-19 infections including

\begin{tabular}{|c|c|c|c|}
\hline $\begin{array}{l}\text { Affected organ } \\
\text { system }\end{array}$ & Symptoms & $\begin{array}{l}\text { Frequency of } \\
\text { involvement (\%) }\end{array}$ & Refs \\
\hline \multirow[t]{13}{*}{ Cardiovascular } & Shock & $40-80$ & 210,234-236 \\
\hline & Cardiac arrhythmias & 2 & 235 \\
\hline & Abnormal ST- or T-wave segment & 22 & 235 \\
\hline & Prolonged QT interval & 2 & 235 \\
\hline & Pericardial effusion & $13-28$ & 235,246 \\
\hline & Decreased LVEF by echo & $31-58$ & 234,235 \\
\hline & Increased troponin & $68-95$ & 234,235 \\
\hline & Myocarditis & $36-87$ & $210,236,246$ \\
\hline & Coronary artery dilation on CT & 27 & 235 \\
\hline & Coronary artery aneurysm & $14-48$ & 234-236 \\
\hline & Mild & 22 & 235 \\
\hline & Moderate & 7 & 235 \\
\hline & Giant & 1 & 235 \\
\hline \multirow[t]{7}{*}{ Gastrointestinal } & Gastrointestinal symptoms & $60-100$ & 234-236 \\
\hline & Diarrhoea & $38-72$ & 210,235 \\
\hline & Vomiting & $51-68$ & 210,246 \\
\hline & Abdominal pain & $19-71$ & 210,235 \\
\hline & Ascites & 21 & 235 \\
\hline & Ileitis & 9 & 235 \\
\hline & Colitis & 4 & 235 \\
\hline \multirow[t]{2}{*}{ Ophthalmological } & Conjunctivitis & $32-83$ & $234-236,246,264$ \\
\hline & Periorbital erythema and oedema & 20 & 264 \\
\hline \multirow[t]{2}{*}{ Nervous system } & Neurological symptoms & $13-35$ & $210,235,236,249$ \\
\hline & $\begin{array}{l}\text { Severe symptoms, including encephalopathy, stroke, central } \\
\text { nervous system infection/demyelination, Guillain-Barré } \\
\text { syndrome and acute cerebral oedema }\end{array}$ & 3 & 249 \\
\hline \multirow[t]{6}{*}{ Integumentary } & Rash & $50-70$ & $234,236,246$ \\
\hline & Erythematous skin rash & 62 & 235 \\
\hline & Hyperaemia, oedema or desquamation of extremities & $26-51$ & 235,264 \\
\hline & Malar erythema & 17 & 264 \\
\hline & Skin eruptions & $9-14$ & 264 \\
\hline & Desquamation in groin & 26 & 236 \\
\hline \multirow[t]{4}{*}{ Respiratory } & Upper respiratory tract infection & 34 & 235 \\
\hline & Lower respiratory tract infection & 22 & 235 \\
\hline & Pleural effusion on $\mathrm{CT}$ & 20 & 235 \\
\hline & $\begin{array}{l}\text { Lung involvement on CT (bilateral pulmonary consolidation } \\
\text { and ground-glass opacity) }\end{array}$ & 13 & 235 \\
\hline \multirow[t]{4}{*}{ Mucosal } & Oral mucosa hyperaemia & 41 & 235 \\
\hline & Red and/or cracked lips & $37-49$ & 246,264 \\
\hline & Strawberry tongue & $11-23$ & 246,264 \\
\hline & Lips and oral-cavity changes & 74 & 234,236 \\
\hline \multirow[t]{2}{*}{ Other } & Lymphadenopathy (cervical) & $19-61$ & $235,236,246$ \\
\hline & Extremity changes & $8-52$ & $234,236,246$ \\
\hline
\end{tabular}

LVEF, left ventricular ejection fraction. 


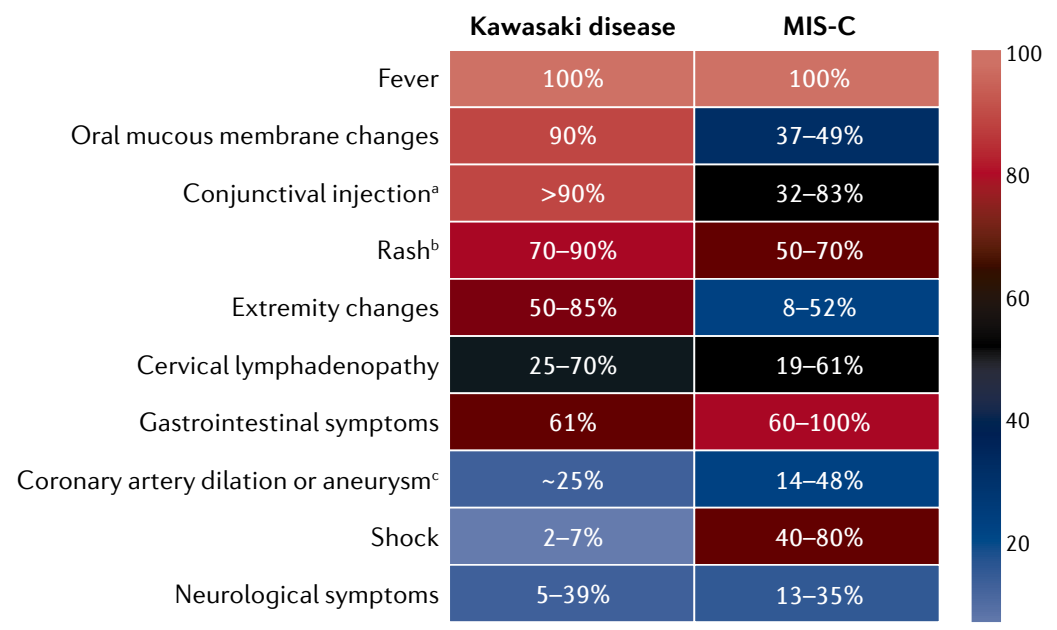

Fig. 3 | Comparative incidence of clinical signs in MIS-C and Kawasaki disease. Percentage incidence of particular symptoms in patients with multisystem inflammatory syndrome in children (MIS-C) or Kawasaki disease is shown, with the values derived from published reports ${ }^{210,231,232,234-236,246,249,250,264-270}$. Although some clinical signs, such as fever and cervical lymphadenopathy are equally prevalent in both MIS-C and Kawasaki disease, the incidence of other symptoms, including shock, coronary artery involvement and gastrointestinal symptoms (vomiting, diarrhoea or abdominal pain), are characteristic of MIS-C. a“Conjunctival injection' refers to bilateral non-exudative conjunctivitis in

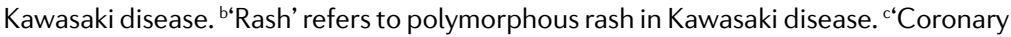
artery dilation of aneurysm' refers to incidence in untreated cases of Kawasaki disease.

MIS-C $(n=616)$, neurological symptoms were noted in $22 \%$ of the patient population $(n=365)$, with most of those affected having transient symptoms ${ }^{249}$. Among these 365 patients, 126 met the criteria for MIS-C. In the patients with neurological involvement $(n=365)$, $43(12 \%)$ had life-threatening neurological involvement (including encephalopathy, stroke, central nervous system infection and/or demyelination, Guillain-Barré syndrome and acute cerebral oedema) and among which $20(47 \%)$ met the criteria for MIS-C. In a study of 286 children with MIS-C located in 55 centres in 17 European countries, neurological involvement was identified in 43 individuals $(15 \%)^{235}$. In a pooled meta-analysis of data from 370 children with MIS-C, 133 (35.9\%) had neurological symptoms ${ }^{210}$ (TABLE 4). Neurological involvement in Kawasaki disease is variable, reportedly affecting $5-39 \%$ of patients ${ }^{250,251}$.

In contrast to those with Kawasaki disease, patients with MIS-C tend to have a worse acute clinical course and multisystem involvement, as illustrated by an increased requirement forintensive care management. A large study of $>1,000$ patients with Kawasaki disease revealed that $2.4 \%$ of these children required intensive care $^{252}$. In stark contrast, an analysis of 783 cases of MIS-C determined that $68 \%$ of patients required intensive care admission, $63 \%$ needed inotropic support, $28 \%$ had some form of respiratory support and $4 \%$ of patients required extra-corporeal membrane oxygenation ${ }^{253}$. Among 1,080 patients with MIS-C, intensive care admission was more likely in children aged $>5$ years old than in younger children, and in non-Hispanic Black patients than in non-Hispanic white patients, and coronary artery abnormalities were more common in boys than in girls ${ }^{254}$. Elevated acute-phase inflammatory markers, troponin, B-type natriuretic peptide and $\mathrm{D}$-dimer levels also identified patents at risk of severe disease ${ }^{254}$. In a study evaluating 29 children with MIS-C in France, severe disease occurred in $52 \%$ of them and was associated with high persistent fever and high levels of inflammatory markers ${ }^{255}$. Although the reason for a more critical illness in the acute phase of MIS-C than in Kawasaki disease is unclear, it is thought to be linked to the cytokine storm in MIS-C 256,257 .

\section{Immunological differences}

In several small studies, comparative immune profiling of children with MIS-C and Kawasaki disease has been performed, to differentiate between these two disease entities. MIS-C is associated with lymphopenia, lower white blood cell and naive $\mathrm{CD} 4^{+} \mathrm{T}$ cell counts, and increased central and effector memory T cell subpopulations, compared with Kawasaki disease ${ }^{103}$. IL-17 is a mediator of inflammation in Kawasaki disease, but is less prominent in MIS- $\mathrm{C}^{103}$. In a comparison of cytokine profiles, levels of circulating IFN $\gamma$ were significantly higher in patients with severe forms of MIS-C than in those with milder MIS-C or Kawasaki disease ${ }^{258}$.

In a study of the immunological profiles of paediatric patients, $75 \%$ of those with MIS-C, but none with Kawasaki disease, TSS or COVID-19, displayed non-HLA-biased, SARS-CoV-2 non-reactive, polyclonal expansion of TCR V $\beta 21.3^{+}$activated $\mathrm{CD}^{+}$ and $\mathrm{CD}^{+} \mathrm{T}$ cells ${ }^{165}$. Notably, these $\mathrm{V} \beta 21.3^{+} \mathrm{T}$ cells had high expression of $\mathrm{CX}_{3} \mathrm{CR} 1$, a marker previously identified on the activated $\mathrm{CD}^{+} \mathrm{T}$ cells of patients with MIS-C ${ }^{185}$. The remarkable specificity of $\mathrm{V} \beta 21.3^{+}$ $\mathrm{T}$ cell subset expansion noted in MIS-C is consistent with superantigen-mediated activation of the immune system $^{163}$, whereas in Kawasaki disease, evidence of a role of superantigens in pathogenesis is lacking ${ }^{50}$.

Autoantibody profiles have been compared in patients with MIS-C and Kawasaki disease ${ }^{103}$. Levels of antibodies to some vascular endothelial cell proteins, such as endoglin, were higher in both groups of patients than in healthy controls, whereas some autoantibodies (such as that to EGF-like repeat and discoidin I-like domain-containing protein 3) were overexpressed in Kawasaki disease compared with MIS-C. To confound matters, plasma levels of endoglin were elevated in both sets of patients compared with healthy children, raising the possibility that antibodies to endothelial cells were the result, rather than the cause, of vascular damage. Another possibility is that the $\mathrm{S}$ protein superantigen of SARS-CoV-2 might cause aberrant activation of $\mathrm{B}$ cells ${ }^{162}$.

Some laboratory parameters are important differentiators between Kawasaki disease and MIS-C. Although both syndromes involve a diffuse hyperinflammatory response, patients with MIS-C tend to have a lower platelet count, lower absolute lymphocyte count and higher levels of C-reactive protein, $\mathrm{N}$-terminal pro-B-type natriuretic peptide, troponin and ferritin ${ }^{16,17,20,94,100-114,164}$. Additionally, coagulation abnormalities are common, including elevation of $\mathrm{D}$-dimer and fibrinogen levels ${ }^{11,12,257,259}$. Hyponatraemia is another common laboratory finding in patients with MIS- $\mathrm{C}^{127}$. The presence 
of burr cells and neutrophils with toxic granulation can also discriminate MIS-C from severe COVID-19 (REF. ${ }^{150}$ ). Finally, evidence of recent SARS-CoV-2 infection, particularly by positive serology, is a diagnostic indicator of MIS-C ${ }^{148,149}$.

\section{Conclusion}

Epidemiological and clinical differences reveal that although MIS-C has phenotypic similarities to Kawasaki disease, they are different syndromes. They have varying degrees of hyperinflammation and dysregulated immune responses ${ }^{131}$. Children with MIS-C are, in general, more critically ill, with prominent gastrointestinal symptoms, cardiac involvement with shock, haematological abnormalities and elevated acute-phase reactants. They have positive SARS-CoV-2 serology, suggesting a link to prior clinical or subclinical infection or exposure. It is likely that a combination of pathogen and host factors is involved in the genesis of an intense aberrant activation of both innate and adaptive immune responses and subsequent cytokine storm ${ }^{16,18}$. Some of the pathogen-related factors include antigen mimicry of host antigens, and superantigen properties of viral proteins. Potential host factors include age and immune-system immaturity, altered intestinal microbiota, nutritional deficiencies and genetic (including inborn errors of immunity) and epigenetic predisposition $^{13}$. However, to what extent each of these factors contributes, and how they interact to cause the clinical syndrome, are relative unknowns that need further exploration. Various lines of evidence based on inflammatory parameters, clinical signs or gene analyses have evoked the possibility that MIS-C is a heterogeneous complex disorder. Current data on the immune signatures in patients with MIS-C are based on small sample size, non-homogeneous cohorts. Hence, analysis of dynamic changes in the immune signatures of patients with MIS-C and their comparison with those with Kawasaki disease in a large homogeneous cohort is needed, to accurately determine the similarities and distinct features of the two disease entities. Nevertheless, with the evidence of elevation of signatures of autoimmunity in MIS-C, and reports of various post-COVID-19 conditions in adults, long-term follow-up of patients with MIS-C might be advisable, because of the possibility of relapse. Notably, however, relapse is rare in Kawasaki disease, which might suggest that recurrence is also unlikely in MIS-C.

While researchers and clinicians navigate the possibilities and evaluate the best treatment options for patients affected by COVID-19-related illnesses, it is imperative to establish registries and dedicated multidisciplinary research teams to investigate the pathogenesis and specific therapeutic strategies in MIS-C. An important step towards this end was the workshop that was convened by the NIH in June 2020, which aimed to bring together the experts on the subject, to initiate dialogue leading to future studies ${ }^{260}$. In conclusion, MIS-C has important epidemiological, clinical and immunological differences from Kawasaki disease, enabling its classification as a separate syndrome. Study of MIS-C will continue to enhance our understanding of these conditions that are related by their association with the cytokine storm phenomenon.

Published online 29 October 2021
1. Lai, C.-C et al. Global epidemiology of coronavirus disease 2019 (COVID-19): disease incidence, daily cumulative index, mortality, and their association with country healthcare resources and economic status. Int. J. Antimicrob. Agents 55, 105946 (2020).

2. Cucinotta, D. \& Vanelli, M. WHO declares COVID-19 a pandemic. Acta Bio Med. Atenei Parm. 91, 157-160 (2020).

3. Bikdeli, B. et al. COVID-19 and thrombotic or thromboembolic disease: implications for prevention, antithrombotic therapy, and follow-up: JACC state-of-the-art review. J. Am. Coll. Cardiol. 75 , 2950-2973 (2020)

4. Montalvan, V., Lee, J., Bueso, T., De Toledo, J. \& Rivas, K. Neurological manifestations of COVID-19 and other coronavirus infections: a systematic review. Clin. Neurol. Neurosurg. 194, 105921 (2020).

5. Clerkin, K. J. et al. COVID-19 and cardiovascular disease. Circulation 141, 1648-1655 (2020).

6. Hoffman, J. I. E. \& Kaplan, S. The incidence of congenital heart disease. J. Am. Coll. Cardiol. 39 , 1890-1900 (2002).

7. Coperchini, F., Chiovato, L., Croce, L., Magri, F. \& Rotondi, M. The cytokine storm in COVID-19: an overview of the involvement of the chemokine/ chemokine-receptor system. Cytokine Growth Factor Rev. 53, 25-32 (2020)

8. Ou, X. et al. Characterization of spike glycoprotein of SARS-CoV-2 on virus entry and its immune cross-reactivity with SARS-CoV. Nat. Commun. 11 1620 (2020)

9. Hoffmann, M. et al. SARS-CoV-2 cell entry depends on ACE2 and TMPRSS2 and Is blocked by a clinically proven protease inhibitor. Cell 181, 271-280 e8 (2020).

10. Liu, J. et al. Longitudinal characteristics of lymphocyte responses and cytokine profiles in the peripheral blood of SARS-CoV-2 infected patients. EBioMedicine 55, 102763 (2020).
11. Verdoni, L et al. An outbreak of severe Kawasaki-like disease at the Italian epicentre of the SARS-CoV-2 epidemic: an observational cohort study. Lancet 395 , 1771-1778 (2020).

An early report of MIS-C from the first wave of COVID-19 in mid-2020.

12. Riphagen, S., Gomez, X., Gonzalez-Martinez, C., Wilkinson, N. \& Theocharis, P. Hyperinflammatory shock in children during COVID-19 pandemic. Lancet 395, 1607-1608 (2020).

An early report of MIS-C from the first wave of COVID-19 in mid-2020

13. Feldstein, L. R. et al. Multisystem inflammatory syndrome in U.S. children and adolescents. N. Engl. J. Med. 383, 334-346 (2020). An early report of MIS-C from the first wave of COVID-19 in mid-2020.

14. Dufort, E. M. et al. Multisystem inflammatory syndrome in children in New York State. N. Engl. J. Med. 383, 347-358 (2020). An early report of MIS-C from the first wave of COVID-19 in mid-2020.

15. Cheung, E. W. et al. Multisystem inflammatory syndrome related to COVID-19 in previously healthy children and adolescents in New York City. JAMA 324 294-296 (2020)

An early report of MIS-C from the first wave of COVID-19 in mid-2020.

16. Galeotti, C. \& Bayry, J. Autoimmune and inflammatory diseases following COVID-19. Nat. Rev. Rheumatol. $16,413-414(2020)$

17. Simpson, J. M. \& Newburger, J. W. Multi-system inflammatory syndrome in children in association with COVID-19. Circulation 142, 437-440 (2020).

18. Levin, M. Childhood multisystem inflammatory syndrome - a new challenge in the pandemic. N. Engl. J. Med. 383, 393-395 (2020).

19. Kawasaki, T. Acute febrile mucocutaneous syndrome with lymphoid involvement with specific desquamation of the fingers and toes in children Arerugi 16 178-222 (1967).

20. McCrindle Brian, W. et al. Diagnosis, treatment, and long-term management of Kawasaki disease: a scientific statement for health professionals from the American Heart Association. Circulation 135 e927-e999 (2017).

21. Burns, J. C. et al. Genetic variations in the receptor-ligand pair CCR5 and CCL3L1 are important determinants of susceptibility to Kawasaki disease. J. Infect. Dis. 192, 344-349 (2005).

22. Burgner, D. et al. A genome-wide association study identifies novel and functionally related susceptibility loci for Kawasaki disease. PLoS Genet. 5, e1000319 (2009).

23. Burgner, D. \& Harnden, A. Kawasaki disease: what is the epidemiology telling us about the etiology? Int. J. Infect. Dis. 9, 185-194 (2005).

24. Son, M. B. F. \& Newburger, J. W. Kawasaki disease. Pediatr. Rev. 39, 78-90 (2018).

25. Burns, J. C. The riddle of Kawasaki disease. N. Engl. J. Med. 356, 659-661 (2007)

26. Holman, R. C., Curns, A. T., Belay, E. D., Steiner, C. A. \& Schonberger, L. B. Kawasaki syndrome hospitalizations in the United States, 1997 and 2000. Pediatrics 112, 495-501 (2003).

27. Kuijpers, T. W. et al. Kawasaki disease: a maturationa defect in immune responsiveness. J. Infect. Dis. 180, 1869-1877 (1999).

28. Green, M. S. The male predominance in the incidence of infectious diseases in children: a postulated explanation for disparities in the literature. Int. J. Epidemiol. 21, 381-386 (1992)

29. Burgner, D. \& Levin, M. Genetic susceptibility to infectious diseases. Pediatr. Infect. Dis. J. 22, 1-6 (2003).

30. Harnden, A., Alves, B. \& Sheikh, A. Rising incidence of Kawasaki disease in England: analysis of hospital admission data. BMJ 324, 1424-1425 (2002). 
31. Bell, D. M., Morens, D. M., Holman, R. C. Hurwitz, E. S. \& Hunter, M. K. Kawasaki syndrome in the United States 1976 to 1980 . Am. J. Dis. Child. 137, 211-214 (1983)

32. Chang, R.-K. R. Hospitalizations for Kawasaki disease among children in the United States, 1988-1997. Pediatrics 109, e87 (2002).

33. Du, Z.-D. et al. Epidemiologic picture of Kawasaki disease in Beijing from 1995 through 1999. Pediatr. Infect. Dis. J. 21, 103-107 (2002)

34. Park, Y.-W. et al. Epidemiologic study of Kawasaki disease in Korea, 1997-1999: comparison with previous studies during 1991-1996. J. Korean Med. Sci. 17, 453-456 (2002)

35. Uehara, R. \& Belay, E. D. Epidemiology of Kawasaki disease in Asia, Europe, and the United States. J. Epidemiol. 22, 79-85 (2012).

36. Yanagawa, H., Yashiro, M., Nakamura, Y., Kawasaki, T. \& Kato, H. Results of 12 nationwide epidemiological incidence surveys of Kawasaki disease in Japan. Arch. Pediatr. Adolesc. Med. 149, 779-783 (1995).

37. Burns, J. C. et al. Seasonality and temporal clustering of Kawasaki syndrome. Epidemiology 16, 220-225 (2005).

38. Nakamura, Y., Yanagawa, I. \& Kawasaki, T. Temporal and geographical clustering of Kawasaki disease in Japan. Prog. Clin. Biol. Res. 250, 19-32 (1987).

39. Yanagawa, H., Nakamura, Y., Kawasaki, T. \& Shigematsu, I. Nationwide epidemic of Kawasaki disease in Japan during winter of 1985-86. Lancet 2, 1138-1139 (1986)

40. Chang, L.-Y. et al. Viral infections associated with Kawasaki disease. J. Formos. Med. Assoc. 113 148-154 (2014)

41. Benseler, S. M. et al. Infections and Kawasaki disease: implications for coronary artery outcome. Pediatrics 116, e760-e766 (2005).

42. Esper, F. et al. Association between a novel human coronavirus and Kawasaki disease. J. Infect. Dis. 191 , 499-502 (2005)

43. Rowley, A. H. et al. Detection of antigen in bronchial epithelium and macrophages in acute Kawasaki disease by use of synthetic antibody. J. Infect. Dis 190, 856-865 (2004).

44. Cohen, E. $\&$ Sundel, R. Kawasaki disease at 50 years. JAMA Pediatr. 170, 1093-1099 (2016).

45. Rowley, A. H. Is Kawasaki disease an infectious disorder? Int. J. Rheum. Dis. 21, 20-25 (2018)

46. Abe, J. et al. Selective expansion of T cells expressing T-cell receptor variable regions $\mathrm{V} \beta 2$ and $\mathrm{V} \beta 8$ in Kawasaki disease. Proc. Natl Acad. Sci. USA 89 4066-4070 (1992).

47. Abe, J. et al. Characterization of T cell repertoire changes in acute Kawasaki disease. J. Exp. Med. 177 791-796 (1993)

48. Curtis, N., Zheng R. Lamb, J. R. \& Levin, M Evidence for a superantigen mediated process in Kawasaki disease. Arch. Dis. Child. 72, 308-311 (1995).

49. Nagata, S. et al. Heat shock proteins and superantigenic properties of bacteria from the gastrointestinal tract of patients with Kawasaki disease. Immunology 128, 511-520 (2009).

50. Pietra, B. A., Inocencio, J. D., Giannini, E. H. \& Hirsch, R. TCR V $\beta$ family repertoire and T cell activation markers in Kawasaki disease. J. Immunol. 153, 1881-1888 (1994).

51. Mancia, L. et al. Characterization of the T-cell receptor $\mathrm{V}-\beta$ repertoire in Kawasaki disease. Scand. J. Immunol. 48, 443-449 (1998)

52. Jun, J. S., Jung, Y. K. \& Lee, D. W. Relationship between vitamin $D$ levels and intravenous immunoglobulin resistance in Kawasaki disease. Korean J. Pediatr. 60, 216-220 (2017)

53. Canning, M. O., Grotenhuis, K., de Wit, H., Ruwhof, C. \& Drexhage, H. A. 1-a,25-Dihydroxyvitamin D3 $(1,25(\mathrm{OH})(2) \mathrm{D}(3))$ hampers the maturation of fully active immature dendritic cells from monocytes. Eur. J. Endocrinol. 145, 351-357 (2001).

54. Ben-Shoshan, M. et al. 1 $\alpha, 25$-dihydroxyvitamin D3 (Calcitriol) inhibits hypoxia-inducible factor-1/vascular endothelial growth factor pathway in human cancer cells. Mol. Cancer Ther. 6, 1433-1439 (2007).

55. Meyer, K. et al. Breastfeeding and vitamin D supplementation reduce the risk of Kawasaki disease in a German population-based case-control study. BMC Pediatr. 19, 66 (2019).

56. Stagi, S., Rigante, D., Lepri, G., Matucci Cerinic, M. \& Falcini, F. Severe vitamin D deficiency in patients with Kawasaki disease: a potential role in the risk to develop heart vascular abnormalities? Clin. Rheumatol. 35 1865-1872 (2016)

57. Chen, Y.-L., Wang, J.-L. \& Li, W.-O. Prediction of the risk of coronary arterial lesions in Kawasaki disease by serum 25-hydroxyvitamin D3. Eur. J. Pediatr. 173 1467-1471 (2014).

58. Kim, S. \& Eun, L. Y. Iron deficiency anemia as a predictor of coronary artery abnormalities in Kawasaki disease. Korean J. Pediatr. 62, 301-306 (2019).

59. Belkaid, Y. \& Hand, T. Role of the microbiota in immunity and inflammation. Cell 157, 121-141 (2014).

60. Kaneko, K., Akagawa, S., Akagawa, Y., Kimata, T. \& Tsuji, S. Our evolving understanding of Kawasaki disease pathogenesis: role of the gut microbiota. Front. Immunol. 11, 1616 (2020).

61. Yamashiro, Y., Nagata, S., Ohtsuka, Y., Oguchi, S. $\varnothing$ Shimizu, T. Microbiologic studies on the small intestine in Kawasaki disease. Pediatr. Res. 39 622-624 (1996)

62. Takeshita, S., Kobayashi, I., Kawamura, Y., Tokutomi, T $\&$ Sekine, I. Characteristic profile of intestinal microflora in Kawasaki disease. Acta Paediatr. 91 783-788 (2002)

63. Chen, J. et al. Altered gut microbiota correlated with systemic inflammation in children with Kawasaki disease. Sci. Rep. 10, 14525 (2020).

64. Kumrah, R., Vignesh, P., Rawat, A. \& Singh, S. Immunogenetics of Kawasaki disease. Clin. Rev. Allergy Immunol. 59, 122-139 (2020).

65. Holman, R. C. et al. Kawasaki syndrome in Hawaii. Pediatr. Infect. Dis. J. 24, 429-433 (2005).

66. Fujita, Y. et al. Kawasaki disease in families. Pediatrics 84, 666-669 (1989)

67. Onouchi, Y. et al. Common variants in CASP3 confer susceptibility to Kawasaki disease. Hum. Mol. Gene 19, 2898-2906 (2010)

The results of this study indicate that multiple variants in the caspase 3 gene (CASP3) confer susceptibility to Kawasaki disease.

68. Shimizu, C. et al. Transforming growth factor-beta signaling pathway in patients with Kawasaki disease. Circ. Cardiovasc. Genet. 4, 16-25 (2011).

69. Chang, L., Yang, H.-W., Lin, T.-Y. \& Yang, K. D. Perspective of immunopathogenesis and immunotherapies for Kawasaki disease. Front. Pediatr 9, 697632 (2021)

70. Alphonse, M. P. et al. Inositol-triphosphate 3-kinase c mediates inflammasome activation and treatmen response in Kawasaki disease. J. Immunol. 197 3481-3489 (2016).

71. Onouchi, Y. Molecular genetics of Kawasaki disease Pediatr. Res. 65, 46R-54R (2009).

72. Burns, J. C. Cyclosporine and coronary outcomes in Kawasaki disease. J. Pediatr. 210, 239-242 (2019)

73. Matsuda, I., Hattori, S., Nagata, N., Fruse, A. \& Nambu, H. HLA antigens in mucocutaneous lymph node syndrome. Am. J. Dis. Child 131, 1417-1418 (1977).

74. Kato, S. et al. HLA antigens in Kawasaki disease. Pediatrics 61, 252-255 (1978).

75. Krensky, A. M., Berenberg, W., Shanley, K. \& Yunis, E. J. HLA antigens in mucocutaneous lymph node syndrome in New England. Pediatrics 67 741-743 (1981)

76. Sharma, K. et al. Epigenetics in Kawasaki disease Front. Pediatr. 9, 626 (2021).

77. Assari, R. et al. Pro-inflammatory cytokine single nucleotide polymorphisms in Kawasaki disease. Int. J. Rheum. Dis. 21, 1120-1126 (2018)

78. Weng, K.-P. et al. IL-1B polymorphism in association with initial intravenous immunoglobulin treatment failure in Taiwanese children with Kawasaki disease. Circ. J. 74, 544-551 (2010).

79. Kim, J.-J. et al. Identification of KCNN2 as a susceptibility locus for coronary artery aneurysms in Kawasaki disease using genome-wide association analysis. J. Hum. Genet. 58, 521-525 (2013)

80. Kwon, Y.-C. et al. Identification of the TIFAB gene as a susceptibility locus for coronary artery aneurysm in patients with Kawasaki disease. Pediatr. Cardiol. 40 483-488 (2019)

81. Lu, Z. et al. P2RY12:rs7637803 TT variant genotype increases coronary artery aneurysm risk in Kawasak disease in a southern Chinese population. J. Gene Med. 21, e3066 (2019)

82. $\mathrm{Fu}, \mathrm{L}$. Y. et al. The IL-1B gene polymorphisms rs 16944 and rs 1143627 contribute to an increased risk of coronary artery lesions in southern Chinese children with Kawasaki disease. J. Immunol. Res. 2019, 4730507 (2019).

83. Hara, T. et al. Kawasaki disease: a matter of innate immunity. Clin. Exp. Immunol. 186, 134-143 (2016).
84. Lee, N. H., Choi, H. J. \& Kim, Y. H. Clinical usefulness of serum procalcitonin level in distinguishing between Kawasaki disease and other infections in febrile children. Korean J. Pediatr. 60, 112-117 (2017)

85. Tremoulet, A. H. et al. Increased incidence and severity of Kawasaki disease among Filipino-Americans in San Diego county. Pediatr. Infect. Dis. J. 30, 909-911 (2011)

86. Burns, J. C. \& Glodé, M. P. Kawasaki syndrome. Lancet 364, 533-544 (2004)

87. Ikeda, K. et al. Unique activation status of peripheral blood mononuclear cells at acute phase of Kawasaki disease Clin Exp. Immunol 160, 246-255 (2010)

88. Armaroli, G. et al. Monocyte-derived interleukin-1 $\beta$ as the driver of S100A 12 -induced sterile inflammatory activation of human coronary artery endothelial cells: implications for the pathogenesis of Kawasaki disease. Arthritis Rheumatol. 71, 792-804 (2019).

This article provides mechanistic insight on the roles of S100A1 2 and IL-1 $\beta$ in the pathogenesis of Kawasaki disease, and supports the therapeutic use of IL- $1 \beta$ inhibitors.

89. Zhang, K. et al. Increase in Thelper type 17 cells in children with Kawasaki disease is NR4A2 dependent. Eur. J. Inflamm. 16, 2058739218760945 (2018).

90. $\mathrm{Wu}, \mathrm{Y}$. et al. Interleukin- 6 is prone to be a candidate biomarker for predicting incomplete and IVIC nonresponsive Kawasaki disease rather than coronary artery aneurysm. Clin. Exp. Med. 19, 173-181 (2019).

91. Oharaseki, T. et al. The role of TNF- $\alpha$ in a murine model of Kawasaki disease arteritis induced with a Candida albicans cell wall polysaccharide. Mod. Rheumatol. 24, 120-128 (2014).

92. Lin, C. Y., Lin, C. C., Hwang, B. \& Chiang, B. Serial changes of serum interleukin- 6 , interleukin- 8 , and tumor necrosis factor alpha among patients with Kawasaki disease. J. Pediatr. 121, 924-926 (1992).

93. Guo, M. M.-H. et al. Th17- and Treg-related cytokine and mRNA expression are associated with acute and resolving Kawasaki disease. Allergy 70, 310-318 (2015)

94. Lin, C.-Y., Lin, C.-C., Hwang, B. \& Chiang, B. N. Cytokines predict coronary aneurysm formation in Kawasaki disease patients. Eur. J. Pediatr. 152, 309-312 (1993)

95. Rahmani, F. et al. Interleukin 10 and and transforming growth factor $\beta$ polymorphisms as risk factors or Kawasaki disease: a case-control study and meta-analysis. Avicenna J. Med. Biotechnol. 11 325-333 (2019).

96. Jia, S., Li, C., Wang, G., Yang, J. \& Zu, Y. The Thelper type $17 /$ regulatory $T$ cell imbalance in patients with acute Kawasaki disease. Clin. Exp. Immunol. 162, 131-137 (2010)

97. Yoshida, Y et al. Enhanced formation of neutrophil extracellular traps in Kawasaki disease. Pediatr. Res. 87, 998-1004 (2020)

98. Papayannopoulos, V. Neutrophil extracellular traps in immunity and disease. Nat. Rev. Immunol. 18 , 134-147 (2018).

99. Garcia-Romo, G. S. et al. Netting neutrophils are major inducers of type I IFN production in pediatric systemic lupus erythematosus. Sci. Transl. Med. 3 , 73 ra20 (2011).

100. Kessenbrock, K. et al. Netting neutrophils in autoimmune small-vessel vasculitis. Nat. Med. 15, 623-625 (2009).

101. Corsiero, E., Pratesi, F., Prediletto, E., Bombardieri, M $\&$ Migliorini, P. NETosis as source of autoantigens in rheumatoid arthritis. Front Immunol 7,485 (2016).

102. Grunebaum, E. et al. The role of anti-endothelial cell antibodies in Kawasaki disease - in vitro and in vivo studies. Clin. Exp. Immunol. 130, 233-240 (2002)

103. Consiglio, C. R. et al. The immunology of multisystem inflammatory syndrome in children with COVID-19. Cell 183, 968-981.e7 (2020). On the basis of systems-level analyses of various immune cells, cytokines and autoantibodies, this article identifies shared and distinct immunological features of MIS-C and Kawasaki disease.

104. Sakurai, Y. Autoimmune aspects of Kawasaki disease. J. Investig. Allergol. Clin. Immunol. 29, 251-261 (2019).

105. Nash, M. C., Shah, V., Reader, J. A. \& Dillon, M. J. Anti-neutrophil cytoplasmic antibodies and anti-endothelial cell antibodies are not increased in Kawasaki disease. Rheumatology 34, 882-887 (1995).

106. Li, C. R., Yang, X. Q., Shen, J., Li, Y. B. \& Jiang, L. P. Immunoglobulin $\mathrm{G}$ subclasses in serum and circulating immune complexes in patients with Kawasaki syndrome. Pediatr. Infect. Dis. J. 9 544-547 (1990). 
107. Levin, M. et al. Platelet immune complex interaction in pathogenesis of Kawasaki disease and childhood polyarteritis. Br. Med. J. Clin. Res. Ed. 290 1456-1460 (1985)

108. Miyata, K. et al. Circulation immune complexes and granulocytes chemotaxis in Kawasaki disease: the 8th conference on prevention for rheumatic fever and rheumatic heart disease. Jpn. Circ. J. 48 1350-1353 (1984)

109. Ono, S., Onimaru, T., Kawakami, K., Hokonohara, M \& Miyata, K. Impaired granulocyte chemotaxis and increased circulating immune complexes in Kawasaki disease. J. Pediatr. 106, 567-570 (1985)

110. Kohsaka, T., Abe, J., Asahina, T. \& Kobayashi, N. Classical pathway complement activation in Kawasaki syndrome. J. Allergy Clin. Immunol. 93, 520-525 (1994).

111. Biezeveld, M. H. et al. Polymorphisms in the mannose-binding lectin gene as determinants of age-defined risk of coronary artery lesions in Kawasaki disease. Arthritis Rheum. 54, 369-376 (2006).

112. Ohshio, G. et al. High levels of IgA-containing circulating immune complex and secretory IgA in Kawasaki disease. Microbiol. Immunol. 31, 891-898 (1987).

113. Noval Rivas, M. \& Arditi, M. Kawasaki disease: pathophysiology and insights from mouse models. Nat. Rev. Rheumatol. 16, 391-405 (2020).

114. Noval Rivas, M. et al. Intestinal permeability and IgA provoke immune vasculitis linked to cardiovascula inflammation. Immunity 51, 508-521.e6 (2019).

115. Olivito, B. et al. Defective FOXP3 expression in patients with acute Kawasaki disease and restoration by intravenous immunoglobulin therapy. Clin. Exp. Rheumatol. 28, 93-97 (2010).

116. Abe, J. et al. Gene expression profiling of the effect of high-dose intravenous Ig in patients with Kawasaki disease. J. Immunol. 174, 5837-5845 (2005).

117. Yoshimura, K. et al. Increased nitric oxide production by neutrophils in early stage of Kawasaki disease. Eur. J. Pediatr. 168, 1037-1041 (2009).

118. Wang, Y. et al. Evaluation of intravenous immunoglobulin resistance and coronary artery lesions in relation to Th1/Th2 cytokine profiles in patients with Kawasaki disease. Arthritis Rheum. 65 , 805-814 (2013).

119. Zhu, Y. P. et al. Immune response to intravenous immunoglobulin in patients with Kawasaki disease and MIS-C. J. Clin. Invest. https://doi.org/10.1172 JCI147076 (2021).

120. Wang, Z. et al. Single-cell RNA sequencing of peripheral blood mononuclear cells from acute Kawasaki disease patients. Nat. Commun. 12, 5444 (2021)

This article applies single-cell RNA sequencing to report that monocytes are the major contributors of inflammatory responses, including IL- $1 \beta$ and TNF, in Kawasaki disease.

121. Rambabu, N., Mathew, M. J., Kaveri, S. V. \& Bayry, J. Boolean analysis of the transcriptomic data to identify novel biomarkers of IVIG response. Autoimmun. Rev. 20, 102850 (2021)

122. Belhadjer, Z. et al. Acute heart failure in multisystem inflammatory syndrome in children (MIS-C) in the context of global SARS-CoV-2 pandemic. Circulation 142, 429-436 (2020).

123. CDC. Multisystem Inflammatory Syndrome in Children (MIS-C) Associated with Coronavirus Disease 2019 (COVID-19). Health Alert Network https://emergency. cdc.gov/han/2020/han00432.asp (2020).

124. CDC. COVID Data Tracker. https://covid.cdc.gov/ covid-data-tracker (2020).

125. Kaushik, S. et al. Multisystem inflammatory syndrome in children associated with severe acute respiratory syndrome coronavirus 2 infection (MIS-C): a multi-institutional study from New York City. J. Pediatr. 224, 24-29 (2020).

126. Davies, P. et al. Intensive care admissions of children with paediatric inflammatory multisystem syndrome temporally associated with SARS-CoV-2 (PIMS-TS) in the UK: a multicentre observational study. Lancet Child Adolesc. Health 4, 669-677 (2020).

127. Pouletty, M. et al. Paediatric multisystem inflammatory syndrome temporally associated with SARS-CoV-2 mimicking Kawasaki disease (Kawa-COVID-19): a multicentre cohort. Ann. Rheum. Dis. 79, 999-1006 (2020). An early report of MIS-C from the first wave of COVID-19 in mid-2020.

128. Toubiana, J. et al. Kawasaki-like multisystem inflammatory syndrome in children during the covid-19 pandemic in Paris, France: prospective observational study. BMJ 369, m2094 (2020). An early report of MIS-C from the first wave of COVID-19 in mid-2020.

129. Capone, C. A. et al. Characteristics, cardiac involvement, and outcomes of multisystem inflammatory syndrome of childhood associated with severe acute respiratory syndrome coronavirus 2 Infection. J. Pediatr. 224, 141-145 (2020).

130. Hameed, S. et al. Spectrum of imaging findings on chest radiographs, US, CT, and MRI images in multisystem inflammatory syndrome in children (MIS-C) associated with COVID-19. Radiology 298 E1-E10 (2020).

131. Whittaker, E. et al. Clinical characteristics of 58 children with a pediatric inflammatory multisystem syndrome temporally associated with SARS-CoV-2. JAMA 324, 259-269 (2020).

132. Moraleda, C. et al. Multi-inflammatory syndrome in children related to SARS-CoV-2 in Spain. Clin. Infect Dis. 72, e397-e401 (2020).

133. Dhanalakshmi, K. et al. Epidemiological and clinical profile of pediatric inflammatory multisystem syndrome - temporally associated with SARS-CoV-2 (PIMS-TS) in Indian children. Indian. Pediatr. 57, 1010-1014 (2020).

134. Miller, J. et al. Gastrointestinal symptoms as a major presentation component of a novel multisystem inflammatory syndrome in children that is related to coronavirus disease 2019: a single center experience of 44 cases. Gastroenterology 159, 1571-1574.e2 (2020).

135. Belot, A. et al. SARS-CoV-2-related paediatric inflammatory multisystem syndrome, an epidemiological study, France, 1 March to 17 May 2020. Eurosurveillance 25, 2001010 (2020).

136. Lee, P. Y. et al. Distinct clinical and immunological features of SARS-CoV-2-induced multisystem inflammatory syndrome in children. J. Clin. Invest. 130, 5942-5950 (2020)

137. Riollano-Cruz, M. et al. Multisystem inflammatory syndrome in children related to COVID-19: a New York City experience. J. Med. Virol. 93, 424-433 (2021).

138. Ramcharan, T. et al. Paediatric inflammatory multisystem syndrome: temporally associated with SARS-CoV-2 (PIMS-TS): cardiac features, management and short-term outcomes at a UK tertiary paediatric hospital. Pediatr Cardiol. 41, 1391-1401 (2020).

139. Grimaud, M. et al. Acute myocarditis and multisystem inflammatory emerging disease following SARS-CoV-2 infection in critically ill children. Ann. Intensive Care 10, 69 (2020)

140. Perez-Toledo, M. et al. SARS-CoV-2-specific IgG $1 / \operatorname{lgG} 3$ but not IgM in children with pediatric inflammatory multi-system syndrome. Pediatr. Allergy Immunol. 32 1125-1129 (2021)

141. RCPCH. Paediatric multisystem inflammatory syndrome temporally associated with COVID-19. https://www.rcpch.ac.uk/resources/guidance-paediatricmultisystem-inflammatory-syndrome-temporallyassociated-covid-19 (2020).

142. WHO. Multisystem inflammatory syndrome in children and adolescents temporally related to COVID-19. https://www.who.int/news-room/commentaries/detail/ multisystem-inflammatory-syndrome-in-childrenand-adolescents-with-covid-19 (2020)

143. Carlin, R. F. et al. Discriminating multisystem inflammatory syndrome in children requiring treatment from common febrile conditions in outpatient settings. J. Pediatr. 229, 26-32.e2 (2021).

144. Roberts, J. E. et al. Differentiating multisystem inflammatory syndrome in children: a single-centre retrospective cohort study. Arch. Dis. Child. https:/ doi.org/10.1136/archdischild-2021-322290 (2021).

145. García-Salido, A. et al. Severe manifestations of SARS-CoV-2 in children and adolescents: from COVID-19 pneumonia to multisystem inflammatory syndrome: a multicentre study in pediatric intensive care units in Spain. Crit. Care 24, 666 (2020).

146. Hoang, A. et al. COVID-19 in 7780 pediatric patients: a systematic review. EClinicalMedicine 24, 100433 (2020).

147. Mahase, E. Covid-19: cases of inflammatory syndrome in children surge after urgent alert. BMJ 369, m 1990 (2020).

148. Henderson, L. A. et al. American College of Rheumatology clinical guidance for multisystem inflammatory syndrome in children associated with SARS-CoV-2 and Hyperinflammation in pediatric COVID-19: Version 1. Arthritis Rheumatol. 72, 1791-1805 (2020).

Guidelines article on the management of MIS-C.
149. Henderson, L. A et al. American College of Rheumatology clinical guidance for multisystem inflammatory syndrome in children associated with SARS-CoV-2 and hyperinflammation in pediatric COVID-19: Version 2. Arthritis Rheumatol. 73. e13-e29 (2021).

Guidelines article on the management of MIS-C.

150. Diorio, C. et al. Multisystem inflammatory syndrome in children and COVID-19 are distinct presentations of SARS-CoV-2. J. Clin. Invest. 130, 5967-5975 (2020).

151. Duarte-Neto, A. N. et al. An autopsy study of the spectrum of severe COVID-19 in children: from SARS to different phenotypes of MIS-C. EclinicalMed 35 100850 (2021).

152. Yonker, L. M. et al. Multisystem inflammatory syndrome in children is driven by zonulin-dependent loss of gut mucosal barrier. J. Clin. Invest. 131 149633 (2021)

A report on the implication of zonulin-dependent loss of intestinal mucosal permeability in the pathogenesis of MIS-C and the therapeutic application of zonulin antagonist larazotide.

53. Ramaswamy, A. et al. Immune dysregulation and autoreactivity correlate with disease severity in SARS-CoV-2-associated multisystem inflammatory syndrome in children. Immunity 54, 1083-1095.e7 (2021).

Use of single-cell RNA sequencing, flow cytometry, unbiased serum proteomics and TCR repertoire analysis to identify the signatures of severity in MIS-C.

154. Gruber, C. N. et al. Mapping systemic inflammation and antibody responses in multisystem inflammatory syndrome in children (MIS-C). Cell 183, 982-995.e14 (2020).

Mapping of systemic inflammation and autoantibodies in MIS-C

155. Rostad, C. A. et al. Quantitative SARS-CoV-2 serology in children with multisystem inflammatory syndrome (MIS-C). Pediatrics 146, e2020018242 (2020)

156. Weisberg, S. P. et al. Distinct antibody responses to SARS-CoV- 2 in children and adults across the COVID-19 clinical spectrum. Nat. Immunol. 22, 25-31 (2021)

157. Anderson, E. M et al SARS-CoV-2 antibody responses in children with MIS-C and mild and severe COVID-19. J. Pediatr. Infect. Dis. Soc. 10, 669-673 (2020).

158. Bartsch, Y. C. et al. Humoral signatures of protective and pathological SARS-CoV-2 infection in children. Nat. Med. 27, 454-462 (2021).

This article reports that children with MIS-C maintain FcyR-binding, inflammatory monocyte/ macrophage-activating SARS-CoV-2 IgG antibodies.

159. Mateus, J. et al. Selective and cross-reactive SARS-CoV-2 T cell epitopes in unexposed humans. Science 370, 89-94 (2020).

160. Grifoni, A. et al. Targets of T cell responses to SARS-CoV-2 coronavirus in humans with COVID-19 disease and unexposed individuals. Cell 181 1489-1501.e15 (2020).

161. Sermet-Gaudelus, I. et al. Prior infection by seasonal coronaviruses, as assessed by serology, does not prevent SARS-CoV-2 infection and disease in children, France, April to June 2020. Eur. Surveill. 26 2001782 (2021)

162. Rivas, M. N., Porritt, R. A., Cheng, M. H., Bahar, I. \& Arditi, M. COVID-19-associated multisystem inflammatory syndrome in children (MIS-C): a novel disease that mimics toxic shock syndrome - the superantigen hypothesis. J. Allergy Clin. Immunol. 147, 57-59 (2021)

163. Cheng, M. H. et al. Superantigenic character of an insert unique to SARS-CoV-2 spike supported by skewed TCR repertoire in patients with hyperinflammation Proc Natl Acad. Sci. USA 117 25254-25262 (2020). Evidence that SARS-CoV-2 spike protein acts as a superantigen leading to HLA class -associated expansion of TRBV11-2 T cells in MIS-C.

164. Porritt, R. A. et al. HLA class I-associated expansion of TRBV 11-2 T cells in multisystem inflammatory syndrome in children. J. Clin. Invest. 131, e 146614 (2021).

Evidence that SARS-CoV-2 spike protein acts as a superantigen leading to HLA class I-associated expansion of TRBV11-2 T cells in MIS-C.

165. Moreews, M. et al. Polyclonal expansion of TCR V $\beta$ $21.3^{+} \mathrm{CD}^{+}$and $\mathrm{CD} 8^{+}+$cells is a hallmark of 
multisystem inflammatory syndrome in children. Sci. Immunol. 6, eabh1516 (2021).

Patients with MIS-C present a unique $\mathrm{CD4}^{+}$and $\mathrm{CD}^{+} \mathrm{T}$ cell TCR repertoire with a polyclonal expansion of $\mathrm{CX}_{3} \mathrm{CR} 1$-expressing activated (TRBV11-2)/V $\beta 21.3^{+}$clonotype.

166. McCormick, J. K., Yarwood, J. M \& Schlievert, P. M. Toxic shock syndrome and bacterial superantigens: an update. Annu. Rev. Microbiol. 55, 77-104 (2001).

167. Radujkovic, A. et al. Vitamin D deficiency and outcome of COVID-19 patients. Nutrients 12, 2757 (2020)

168. Urashima, M. et al. Randomized trial of vitamin D supplementation to prevent seasonal influenza $A$ in schoolchildren. Am. J. Clin. Nutr. 91, 1255-1260 (2010).

169. Omenetti, S. \& Pizarro, T. T. The $\mathrm{T}_{\mathrm{reg}} / \mathrm{T}_{\mathrm{H}} 17$ axis: a dynamic balance regulated by the gut microbiome. Front. Immunol. 6, 639 (2015).

170. Yeoh, Y. K. et al. Gut microbiota composition reflects disease severity and dysfunctional immune responses in patients with COVID-19. Gut 70, 698-706 (2021).

171. Zuo, T. et al. Alterations in fecal fungal microbiome of patients with COVID-19 during time of hospitalization until discharge. Gastroenterology 159, 1302-1310. e5 (2020).

172. Merenstein, C. et al. Signatures of COVID-19 severity and immune response in the respiratory tract microbiome. mBio 12, e0177721 (2021).

173. Zuo, T. et al. Alterations in gut microbiota of patients with COVID-19 during time of hospitalization. Gastroenterology 159, 944-955 e8 (2020).

174. Xu, R. et al. Progressive deterioration of the upper respiratory tract and the gut microbiomes in children during the early infection stages of COVID-19. J. Genet. Genomics https://doi.org/10.1016/j jgg.2021.05.004 (2021).

175. Hurst, J. H. et al. Age-related changes in the upper respiratory microbiome are associated with SARS-CoV-2 susceptibility and illness severity. Preprint at medRxiv https://www.medrxiv.org content/10.1101/2021.03.20.21252680v1 (2021).

176. Chou, J. et al. Mechanisms underlying genetic susceptibility to multisystem inflammatory syndrome in children (MIS-C). J. Allergy Clin. Immunol. 148 732-738.e 1 (2021).

177. Belay, E. D. et al. Trends in geographic and temporal distribution of US children with multisystem inflammatory syndrome during the COVID-19 pandemic. JAMA Pediatr. 175, 837-845 (2021).

178. Krishnan, L., Ogunwole, S. M. \& Cooper, L. A. Historical insights on coronavirus disease 2019 (COVID-19), the 1918 influenza pandemic, and racial disparities: illuminating a path forward. Ann. Intern. Med. 173, 474-481 (2020)

179. Alcendor, D. J. Racial disparities-associated COVID-19 mortality among minority populations in the US. J. Clin. Med. 9, 2442 (2020).

180. Rafferty, M. S. et al. Multisystem inflammatory syndrome in children (MIS-C) and the coronavirus pandemic: current knowledge and implications for public health. J. Infect. Public Health 14, 484-494 (2021).

181. Nguyen, A. et al. Human leukocyte antigen susceptibility map for severe acute respiratory syndrome coronavirus 2. J. Virol. 94, e00510-e00520 (2020).

182. Zhang, Q. et al. Inborn errors of type I IFN immunity in patients with life-threatening COVID-19. Science 370, eabd4570v (2020)

183. Bastard, P. et al. Insufficient type I IFN immunity underlies life-threatening COVID-19 pneumonia. C. $R$. Biol. 344, 19-25 (2021).

184. Lee, P. Y. et al. Immune dysregulation and multisystem inflammatory syndrome in children (MIS-C) in individuals with haploinsufficiency of SOCS 1 . J. Allergy Clin. Immunol. 146, 1194-1200.e1 (2020). This article provides the first evidence on genetic susceptibility to MIS-C.

185. Vella, L. A. et al. Deep immune profiling of MIS-C demonstrates marked but transient immune activation compared to adult and pediatric COVID-19. Sci. Immunol. 6, eabf7570 (2021).

The article identifies a unique and strong activation of vascular patrolling $\mathrm{CX}_{3} \mathrm{CR} 1^{+} \mathrm{CD8}^{+} \mathrm{T}$ cells in MIS-C

186. Carter, M. J. et al. Peripheral immunophenotypes in children with multisystem inflammatory syndrome associated with SARS-CoV-2 infection. Nat. Med. 26 1701-1707 (2020) Based on the immunoprofiling of MIS-C patients, this article suggests that MIS-C might represent a distinct immunopathogenic disease.
187. Pierce, C. A. et al. Immune responses to SARS-CoV-2 infection in hospitalized pediatric and adult patients. Sci. Transl. Med. 12, eabd5487 (2020).

188. Caldarale, F. et al. Plasmacytoid dendritic cells depletion and elevation of IFN- $\gamma$ dependent chemokines CXCL9 and CXCL10 in children with multisystem inflammatory syndrome. Front. Immunol. 12, 654587 (2021).

189. Peart Akindele, N. et al. Distinct cytokine and chemokine dysregulation in hospitalized children with acute COVID-19 and multisystem inflammatory syndrome with similar levels of nasopharyngeal SARS-CoV-2 shedding. J. Infect. Dis. 224, 606-615 (2021).

190. Diorio, C. et al. Proteomic profiling of MIS-C patients reveals heterogeneity relating to interferon gamma dysregulation and vascular endothelial dysfunction. Preprint at medRxiv https://www.medrxiv.org/ content/10.1101/2021.04.13.21255439v1 (2021).

191. Zuo, Y. et al. Neutrophil extracellular traps in COVID-19. JCI Insight 5, e138999 (2020)

192. Middleton, E. A. et al. Neutrophil extracellular traps contribute to immunothrombosis in COVID-19 acute respiratory distress syndrome. Blood 136, 1169-1179 (2020)

193. Yamashita, K., Takaori-Kondo, A. \& Mizugishi, K. Exaggerated neutrophil extracellular trap formation in Kawasaki disease: a key phenomenon behind the outbreak in western countries? Ann. Rheum. Dis. https://doi.org/10.1136/annrheumdis-2020-218593 (2020).

194. Seery, V. et al. Blood neutrophils from children with COVID-19 exhibit both inflammatory and anti-inflammatory markers. EBioMedicine 67, 103357 (2021).

195. Beckmann, N. D. et al. Downregulation of exhausted cytotoxic T cells in gene expression networks of multisystem inflammatory syndrome in children. Nat. Commun. 12, 4854 (2021).

196. Vojdani, A., Vojdani, E. \& Kharrazian, D. Reaction of human monoclonal antibodies to SARS-CoV-2 proteins with tissue antigens: implications for autoimmune diseases. Front. Immunol. 11, 617089 (2020).

197. An, H. \& Park, J. Molecular mimicry map (3M) of SARS-CoV-2: prediction of potentially immunopathogenic SARS-CoV-2 epitopes via a nove immunoinformatic approach. Preprint at bioRxiv https://www.biorxiv.org/content/10.1101/2020. 11.12.344424v1 (2020)

198. European Centre for Disease Prevention and Control. Rapid risk assessment: paediatric inflammatory multisystem syndrome and SARS-CoV-2 infection in children. https://www.ecdc.europa.eu/en/publicationsdata/paediatric-inflammatory-multisystem-syndromeand-sars-cov-2-rapid-risk-assessment (2020).

199. Diorio, C. et al. Evidence of thrombotic microangiopathy in children with SARS-CoV-2 across the spectrum of clinical presentations. Blood Adv. 4 6051-6063 (2020).

200. Whitworth, H. B. et al. Rate of thrombosis in children and adolescents hospitalized with COVID-19 or MIS-C Blood 138, 190-198 (2021).

201. Endo, Y., Takahashi, M. \& Fujita, T. Lectin complement system and pattern recognition. Immunobiology 211 283-293 (2006)

202. Watanabe, Y., Allen, J. D., Wrapp, D., McLellan, J. S $\&$ Crispin, M. Site-specific glycan analysis of the SARS-CoV-2 spike. Science 369, 330-333 (2020).

203. Polycarpou, A., Grigoriadou, S., Klavinskis, L. \& Sacks, S. Does the lectin complement pathway link Kawasaki disease and SARS-CoV-2? Front. Immunol. 11,604512 (2020)

204. Dove, M. L. et al. Multisystem inflammatory syndrome in children: survey of protocols for early hospital evaluation and management. J. Pediatr. 229, 33-40 (2021).

205. Jonat, B. et al. Multisystem inflammatory syndrome in children associated with coronavirus disease 2019 in a children's hospital in New York City: patien characteristics and an institutional protocol for evaluation, management, and follow-up. Pediatr. Crit. Care Med. 22, e178-e191 (2021)

206. Ouldali, N. et al. Association of intravenous immunoglobulins plus methylprednisolone vs immunoglobulins alone with course of fever in multisystem inflammatory syndrome in children. JAMA 325, 855-864 (2021).

207. McArdle, A. J. et al. Treatment of multisystem inflammatory syndrome in children. N. Engl. J. Med. 385, 11-22 (2021) This is an international observational cohort study aimed at supporting the treatment decisions in patients with MIS-C.
208. Guillaume, M.-P., Reumaux, H. \& Dubos, F. Usefulness and safety of anakinra in refractory Kawasaki disease complicated by coronary artery aneurysm. Cardiol. Young. 28, 739-742 (2018).

209. Kone-Paut, I. et al. The use of interleukin 1 receptor antagonist (anakinra) in Kawasaki disease: a retrospective cases series. Autoimmun. Rev. 17 768-774 (2018)

210. Jiang, L. et al. COVID-19 and multisystem inflammatory syndrome in children and adolescents. Lancet Infect. Dis. 20, e276-e288 (2020).

211. Feldstein, L. R. et al. Characteristics and outcomes of US children and adolescents with multisystem inflammatory syndrome in children (MIS-C) compared with severe acute COVID-19. JAMA 325, 1074-1087 (2021).

212. Hoste, L., Van Paemel, R. \& Haerynck, F. Multisystem inflammatory syndrome in children related to COVID-19: a systematic review. Eur. J. Pediatr. 180 2019-2034 (2021).

213. Xu, Q.-Q. et al. Evaluation of left ventricular systolic strain in children with Kawasaki disease. Pediatr. Cardiol. 35, 1191-1197 (2014).

214. Surve, S. V., Joseph, S., Gajbhiye, R. K., Mahale, S. D. $\&$ Modi, D. N. A systematic review on multisystem inflammatory syndrome in children (MIS-C) with COVID-19: development of a scoring system for clinical diagnosis. Preprint at medRxiv https://www. medrxiv.org/content/10.1101/2021.04.23. 21255879v1 (2021).

215. Sahoo, D. et al. An Al-guided invariant signature places MIS-C with Kawasaki disease in a continuum of host immune responses. Preprint at bioRxiv https:// www.biorxiv.org/content/10.1101/2021.04.11 439347v2 (2021)

216. Newburger, J. W. et al. A single intravenous infusion of gamma globulin as compared with four infusions in the treatment of acute Kawasaki syndrome. N. Engl. J. Med. 324, 1633-1639 (1991).

217. Abrams, J. Y. et al. Multisystem inflammatory syndrome in children associated with severe acute respiratory syndrome coronavirus 2 : a systematic review. J. Pediatr. 226, 45-54.e1 (2020).

218. Ouldali, N. et al. Emergence of Kawasaki disease related to SARS-CoV-2 infection in an epicentre of the French COVID-19 epidemic: a time-series analysis. Lancet Child. Adolesc. Health 4, 662-668 (2020).

219. Choe, Y. J. et al. Surveillance of COVID-19-associated multisystem inflammatory syndrome in children, South Korea. Emerg. Infect. Dis. 27, 1196-1200 (2021).

220. Li, W., Tang, Y., Shi, Y., Chen, Y. \& Liu, E. Why multisystem inflammatory syndrome in children has been less commonly described in Asia? Transl. Pediatr. 9, 873-875 (2020).

221. Son, M. B. F. et al. Treatment of Kawasaki disease: analysis of 27 US pediatric hospitals from 2001 to 2006. Pediatrics 124, 1-8 (2009).

222. Coon, E. R., Wilkes, J., Bratton, S. L. \& Srivastava, R. Paediatric overdiagnosis modelled by coronary abnormality trends in Kawasaki disease. Arch. Dis. Child. 103, 937-941 (2018).

223. Ghelani, S. J., Kwatra, N. S. \& Spurney, C. F. Can coronary artery involvement in Kawasaki disease be predicted? Diagnostics 3, 232-243 (2013).

224. Gong, G. W. K., McCrindle, B. W., Ching, J. C. \& Yeung, R. S. M. Arthritis presenting during the acute phase of Kawasaki disease. J. Pediatr. 148, 800-805 (2006).

225. Blondiaux, E. et al. Cardiac MRI in children with multisystem inflammatory syndrome associated with COVID-19. Radiology 297, E283-E288 (2020).

226. Gaitonde, M. et al. COVID-19-related multisystem inflammatory syndrome in children affects left ventricular function and global strain compared with Kawasaki disease. J. Am. Soc. Echocardiogr. 33 , 1285-1287 (2020).

227. Jhaveri, S. et al. Longitudinal echocardiographic assessment of coronary arteries and left ventricular function following multisystem inflammatory syndrome in children. J. Pediatr. 228, 290-293 (2020).

228. Gamez-Gonzalez, L. B. et al. Kawasaki disease shock syndrome: unique and severe subtype of Kawasaki disease. Pediatr. Int. 60, 781-790 (2018).

229. Tsuda, E. et al. Changes in causes of sudden deaths by decade in patients with coronary arterial lesions due to Kawasaki disease. Cardiol. Young. 15, 481-488 (2005).

230. Gatterre, P. et al. Kawasaki disease: an unexpected etiology of shock and multiple organ dysfunction syndrome. Intensive Care Med. 38, 872-878 (2012). 
231. Kanegaye, J. T. et al. Recognition of a Kawasaki disease shock syndrome. Pediatrics 123 , e783-e789 (2009).

232. Li, Y. et al. Kawasaki disease shock syndrome: clinical characteristics and possible use of IL-6, IL-10 and IFN- $\gamma$ as biomarkers for early recognition. Pediatr. Rheumatol. 17, 1 (2019).

233. Ma, L., Zhang, Y.-Y. \& Yu, H.-G. Clinical manifestations of Kawasaki disease shock syndrome. Clin. Pediatr. 57, 428-435 (2018)

234. Alsaied, T. et al. Review of cardiac involvement in multisystem inflammatory syndrome in children. Circulation 143, 78-88 (2021).

235. Valverde, I. et al. Acute cardiovascular manifestations in 286 children with multisystem inflammatory syndrome associated with COVID-19 infection in Europe. Circulation 143, 21-32 (2021).

236. Toubiana, J. et al. Distinctive features of Kawasaki disease following SARS-CoV-2 infection: a controlled study in Paris, France. J. Clin. Immunol. 41, 526-535 (2021).

237. Suzuki, J. et al. Kawasaki disease shock syndrome in Japan and comparison with multisystem inflammatory syndrome in children in European countries. Front. Pediatr. 9, 625456 (2021).

238. Kaneko, K., Takahashi, K., Fujiwara, S., Maruyama, T. \& Obinata, K. Kawasaki disease followed by haemophagocytic syndrome. Eur. J. Pediatr. 157, 610-611 (1998).

239. Cummings, C., McCarthy, P., van Hoff, J. \& Porter, G Kawasaki disease associated with reactive hemophagocytic lymphohistiocytosis. Pediatr. Infect Dis. J. 27, 1116-1118 (2008).

240. Latino, G. A., Manlhiot, C., Yeung, R. S. M., Chahal, N $\&$ McCrindle, B. W. Macrophage activation syndrome in the acute phase of Kawasaki disease. J. Pediatr. Hematol. Oncol. 32, 527-531 (2010).

241. Natoli, V., Rosina, S. \& Ravelli, A. Is macrophage activation syndrome in Kawasaki disease underrecognized? J. Rheumatol. 48, 162-164 (2021).

242. Jinkawa, A et al. Cytokine profile of macrophage activation syndrome associated with Kawasaki disease. Cytokine 119, 52-56 (2019).

243. Aydın, F. et al. Comparison of baseline laboratory findings of macrophage activation syndrome complicating systemic juvenile idiopathic arthritis and multisystem inflammatory syndrome in children. Int. J. Rheum. Dis. 24, 542-547 (2021).

244. Zulian, F. et al. Acute surgical abdomen as presenting manifestation of Kawasaki disease. J. Pediatr. 142. 731-735 (2003)

245. Miyake, T. et al. Small bowel pseudo-obstruction in Kawasaki disease. Pediatr. Radiol. 17, 383-386 (1987).

246. Halepas, S. et al. Oral manifestations of COVID2019-related multisystem inflammatory syndrome in children: a review of 47 pediatric patients. J. Am Dent. Assoc. 152, 202-208 (2021)

247. Saguil, A., Fargo, M. \& Grogan, S. Diagnosis and management of Kawasaki disease. Am. Fam. Physician 91, 365-371 (2015).
248. Chen, T.-H., Kao, W.-T. \& Tseng, Y.-H. Gastrointestinal involvements in children with COVID-related multisystem inflammatory syndrome. Gastroenterology 160, 1887-1888 (2020)

249. LaRovere, K. L. et al. Neurologic involvement in children and adolescents hospitalized in the United States for COVID-19 or multisystem inflammatory syndrome. JAMA Neurol. 78, 536-547 (2021).

250. Dengler, L. D. et al. Cerebrospinal fluid profile in patients with acute Kawasaki disease. Pediatr. Infect. Dis. J. 17, 478-481 (1998)

251. Liu, X. et al. Neurological involvement in Kawasak disease: a retrospective study. Pediatr. Rheumatol. Online J. 18, 61 (2020).

252. Kuo, C.-C. et al. Characteristics of children with Kawasaki disease requiring intensive care: 10 years' experience at a tertiary pediatric hospital. J. Microbiol. Immunol. Infect. 51, 184-190 (2018)

253. Radia, T. et al. Multi-system inflammatory syndrome in children $\&$ adolescents (MIS-C): a systematic review of clinical features and presentation. Paediatr. Respir. Rev. 38, 51-57 (2020)

254. Abrams, J. Y. et al. Factors linked to severe outcomes in multisystem inflammatory syndrome in children (MIS-C) in the USA: a retrospective surveillance study. Lancet Child. Adolesc. Health 5, 323-331 (2021).

255. Ouldali, N. et al. Factors associated with severe SARS-CoV-2 infection. Pediatrics 147, e2020023432 (2021).

256. Ye, Q., Wang, B. \& Mao, J. The pathogenesis and treatment of the 'cytokine storm' in COVID-19. J. Infect. 80, 607-613 (2020)

257. Dolinger, M. T. et al. Pediatric Crohn disease and multisystem inflammatory syndrome in children (MIS-C) and COVID-19 treated with infliximab. J. Pediatr Gastroenterol Nutr 71, 153-155 (2020).

258. Esteve-Sole, A. et al. Similarities and differences between the immunopathogenesis of COVID-19related pediatric multisystem inflammatory syndrome and Kawasaki disease. J. Clin. Invest. 131, e 144554 (2021).

A comparative analysis of circulating cytokines and chemokines to have an insight on the similarities and differences between MIS-C and Kawasaki disease.

259. Al-Ghafry, M. et al. Multisystem inflammatory syndrome in children (MIS-C) and the prothrombotic state: coagulation profiles and rotational thromboelastometry in a MIS-C cohort. J. Thromb. Haemost. 19, 1764-1770 (2021).

260. Martinez, O. M., Bridges, N. D., Goldmuntz, E. \& Pascual, $V$. The immune roadmap for understanding multi-system inflammatory syndrome in children: opportunities and challenges. Nat. Med. 26 1819-1824 (2020).

261. Shobhavat, L. et al. Multisystem inflammatory syndrome in children: clinical features and management-intensive care experience from a pediatric public hospital in western India.
Indian. J. Crit. Care Med. Peer Rev. 24, 1089-1094 (2020).

262. Niño-Taravilla, C., Otaola-Arca, H., Lara-Aguilera, N., Zuleta-Morales, Y. \& Ortiz-Fritz, P. Multisystem inflammatory syndrome in children, Chile, May-August 2020. Emerg. Infect. Dis. 27, 1457-1461 (2021)

263. Tolunay, O. et al. Multisystem inflammatory syndrome in children (MIS-C) associated with COVID-19: a case series experience in a tertiary care hospital of southern Turkey. J. Trop. Pediatr. 67, fmab050 (2021).

264. Young, T. K. et al. Mucocutaneous manifestations of multisystem inflammatory syndrome in children during the COVID-19 pandemic. JAMA Dermatol. 157, 207-212 (2021).

265. Newburger Jane, W. et al. Diagnosis, treatment, and long-term management of Kawasaki disease. Circulation 110, 2747-2771 (2004).

266. Ozdemir, H. et al. Clinical and epidemiological characteristics of children with Kawasaki disease in Turkey. J. Trop. Pediatr. 56, 260-262 (2010).

267. Fukushige, J., Takahashi, N., Ueda, Y. \& Ueda, K. Incidence and clinical features of incomplete Kawasak disease. Acta Paediatr. Oslo. Nor. 83, 1057-1060 (1994).

268. Sung, R. Y. T. et al. Lack of association of cervical lymphadenopathy and coronary artery complications in Kawasaki disease. Pediatr. Infect. Dis. J. 25 521-525 (2006)

269. Smith, L. B., Newburger, J. W. \& Burns, J. C. Kawasaki syndrome and the eye. Pediatr. Infect. Dis. $J$. 8, 116-118 (1989).

270. Baker, A. L. et al. Associated symptoms in the ten days before diagnosis of Kawasaki disease. J. Pediatr 154, 592-595.e2 (2009).

Acknowledgements

The work of J.B. is supported by Agence Nationale de la Recherche, France (Flash COVID-19; ANR-20-COVI-0093COVIMUNE).

\section{Author contributions}

C.S., M.G. and J.B. researched data for the article. C.S., M.C and J.B. wrote the article. All authors provided substantial contribution to discussion of the content, and reviewed and approved the text before submission.

Competing interests

The authors declare no competing interests.

\section{Peer review information}

Nature Reviews Rheumatology thanks H. Bassiri, who co-reviewed with A. Blatz (ECR), and the other, anonymous, reviewer(s) for their contribution to the peer review of this work.

Publisher's note

Springer Nature remains neutral with regard to jurisdictional claims in published maps and institutional affiliations.

(c) Springer Nature Limited 2021 